Influência de bebidas e escovação nas propriedades físicas de uma resina composta

Cesar Penazzo Lepri 

uma resina composta 


\section{INFLUÊNCIA DE BEBIDAS E ESCOVAÇÃO NAS PROPRIEDADES FÍSICAS \\ DE UMA RESINA COMPOSTA}

Dissertação apresentada à Faculdade de Odontologia de Ribeirão Preto da Universidade de São Paulo, para obtenção do título de Mestre em Odontologia Restauradora. Área de concentração: Odontologia Restauradora - Opção: Dentística

Orientadora: Profa. Dra. Regina Guenka Palma Dibb

Ribeirão Preto 
Autorizo a reprodução e/ou divulgação total ou parcial da presente obra por qualquer meio convencional ou eletrônico, desde que seja citada a fonte.

Ficha catalográfica preparada pela Seção de Tratamento da Informação do Serviço de Biblioteca

\section{Lepri, Cesar Penazzo}

Influência de bebidas e escovação nas propriedades físicas de uma resina composta. Ribeirão Preto, 2008.

69p. : il. ; $30 \mathrm{~cm}$

Dissertação de Mestrado, apresentada à Faculdade de Odontologia de Ribeirão Preto/USP. Área de concentração:

Odontologia Restauradora - Opção: Dentística.

Orientadora: Profa. Dra. Regina Guenka Palma-Dibb.

1. Resina composta. 2. Propriedades físicas. 3. Soluções. 4. Escovação. 
Lepri CP. Influência de bebidas e escovação nas propriedades físicas de uma resina composta. [Dissertação de Mestrado]. Ribeirão Preto: Faculdade de Odontologia de Ribeirão Preto da Universidade de São Paulo; 2008.

\section{Banca Examinadora}

Data da Defesa:

Profa. Dra. Regina Guenka Palma Dibb

Instituição:

Julgamento:

Assinatura:

Profa. Dra.

Instituição:

Julgamento:

Assinatura:

Profa. Dra.

Instituição:

Julgamento:

Assinatura: 


\section{DEDICATÓRIA}

A Deus, pelo dom da vida, por iluminar meu caminho, dando-me paz e serenidade.

Aos meus pais, Emílio César Lepri (in memorian) e Leila Maria Penazzo Lepri.

Exemplos de honestidade, trabalho, respeito e caráter; nunca mediram esforços em proporcionar sempre o melhor a seus filhos. Obrigado por tudo!

Aos meus irmãos, Lígia, Taísa e Edgar.

Pelo companheirismo e amizade em todos os momentos da minha vida.

A todos meus familiares que contribuíram, direta ou indiretamente, para a realização deste trabalho. 


\section{AGRADECIMENTO ESPECIAL}

À minha orientadora, Profa. Dra. Regina Guenka Palma Dibb, por ter depositado em mim a confiança para trabalharmos juntos, desde minha graduação. Pela disponibilidade em todos os momentos, orientando-me de fato, sempre de forma segura e objetiva. Agradeço também pelas contribuições para o meu crescimento pessoal e profissional. Muito obrigado. 


\section{AGRADECIMENTOS}

À Faculdade de Odontologia de Ribeirão Preto da Universidade de São Paulo, representada pelo Digníssimo Diretor Prof. Dr. Osvaldo Luiz Bezzon e pelo Vice-Diretor Prof. Dr. Valdemar Mallet da Rocha Barros.

À Coordenação Geral da Pós-Graduação da Faculdade de Odontologia de Ribeirão Preto da Universidade de São Paulo, na pessoa da Profa. Dra. Léa Assed Bezerra da Silva.

À Coordenação do Curso de Pós-Graduação em Odontologia Restauradora da Faculdade de Odontologia de Ribeirão Preto da Universidade de São Paulo, na pessoa do Prof. Dr. Manoel Damião de Sousa Neto.

Ao Chefe do Departamento de Odontologia Restauradora da Faculdade de Odontologia de Ribeirão Preto da Universidade de São Paulo, na pessoa do Prof. Dr. Jesus Djalma Pécora.

À Comissão de Pesquisa da Faculdade de Odontologia de Ribeirão Preto da Universidade de São Paulo, na pessoa da Profa. Dra. Rossana Pereira de Almeida Antunes.

Às Profas. Dras. Maria Cristina Borsatto e Andréa Cândido dos Reis, membros da banca do meu exame de qualificação.

Às Profas. Dras. Silmara Aparecida Milori Corona, Mônica Campos Serra, Telma Nunes do Nascimento e Cecília Pedroso Turssi, docentes do Programa da Pós-Graduação em Odontologia Restauradora da Faculdade de Odontologia de Ribeirão Preto da Universidade de São Paulo.

A Todos Professores do Departamento de Odontologia Restauradora da Faculdade de Odontologia de Ribeirão Preto da Universidade de São Paulo.

À CAPES, pela concessão do auxílio financeiro sob a forma de bolsa de estudo.

Aos colegas da turma de Mestrado em Dentística: Cristiane, Daniel, Francisco, Fernando e Walter. 
Às colegas da turma de Doutorado em Dentística: Alessandra, Aline, Danielle, Juliane e Vivian e também da turma anterior: Daniela, Juliana e Michelle.

Aos colegas da turma de Mestrado em Oclusão: André, Daniel e Giovana.

Aos colegas da turma de Mestrado em Endodontia: Danielle, Doglas e Maurício.

Aos amigos Pedro e Melissa.

Aos amigos Andrigo, Juliano, Márcio.

Aos colegas da $77^{\mathrm{a}}$ Turma FORP-USP que, assim como eu, ingressaram na pósgraduação na FORP: Amanda, Ana Paula, Fabiano e Marta.

A todos os colegas do Laboratório de Dentística: Bruna, Carla, Jaciara, Laura, Maísa, Marcus, Flávio, Renato, Vinícius.

Aos colegas de pós-graduação Diogo, Flávio, Fabrício, Rander e Rodrigo.

Ao Carlos, secretário do Curso de Pós-Graduação em Odontologia Restauradora da Faculdade de Odontologia de Ribeirão Preto da Universidade de São Paulo.

À Isabel e Regiane, secretárias da Seção de Pós-Graduação da Faculdade de Odontologia de Ribeirão Preto da Universidade de São Paulo.

À Amália e Maria Isabel, secretárias do Departamento de Odontologia Restauradora da Faculdade de Odontologia de Ribeirão Preto da Universidade de São Paulo.

À Luiza e Rosângela, funcionárias do Departamento de Odontologia Restauradora da Faculdade de Odontologia de Ribeirão Preto da Universidade de São Paulo.

À técnica Patrícia Marchi, do Laboratório de Pesquisa em Dentística da Faculdade de Odontologia de Ribeirão Preto da Universidade de São Paulo.

Ao técnico Reginaldo Santana, do Laboratório de Pesquisa em Endodontia da Faculdade de Odontologia de Ribeirão Preto da Universidade de São Paulo.

À técnica Ana Cristina, do Laboratório de Bioquímica da Faculdade de Ciências Farmacêuticas de Ribeirão Preto da Universidade de São Paulo. 
Ao técnico Edson Volta, do Laboratório Integrado de Pesquisa em Biocompatibilidade de Materiais da Faculdade de Odontologia de Ribeirão Preto da Universidade de São Paulo.

A todos que, de alguma forma, contribuíram para a realização deste trabalho. 


\section{SUMÁRIO}

$\begin{array}{lr}\text { RESUMO } & 8\end{array}$

$\begin{array}{ll}\text { ABSTRACT } & 10\end{array}$

1 INTRODUÇÃO 12

2 PROPOSIÇÃO 20

3 MATERIAIS E MÉTODOS 22

3.1 Delineamento experimental 23

3.2 Confecção dos corpos-de-prova 23

3.3 Acabamento e polimento dos corpos-de-prova 24

3.4 Avaliação da rugosidade superficial inicial 26

$\begin{array}{lll}3.5 & \text { Análise da cor inicial } & 26\end{array}$

$\begin{array}{ll}3.6 & \text { Ciclagem nas soluções }\end{array}$

$\begin{array}{lll}3.7 & \text { Ensaios de escovação } & 28\end{array}$

3.8 Avaliação da rugosidade superficial final 29

3.9 Análise da cor final 30

3.10 Avaliação da microdureza em profundidade 31

3.11 Análise dos dados 31

$4 \quad$ RESULTADOS

$\begin{array}{lll}4.1 & \text { Estabilidade de cor }\end{array}$

$\begin{array}{lll}4.2 & \text { Rugosidade superficial }\end{array}$

4.3 Microdureza em profundidade 43

$5 \quad$ DISCUSSÃO 45

6 CONCLUSÕES

7 REFERÊNCIAS BIBLIOGRÁFICAS 56

$\begin{array}{lr}\text { ANEXO } & 69\end{array}$ 
Lepri CP. Influência de bebidas e escovação nas propriedades físicas de uma resina composta. [Dissertação de Mestrado]. Ribeirão Preto: Faculdade de Odontologia de Ribeirão Preto da Universidade de São Paulo; 2008.

\section{RESUMO}

Objetivo: Este estudo avaliou a influência de bebidas e escovação na estabilidade de cor, rugosidade superficial e microdureza em profundidade de uma resina composta. Materiais e Método: 120 discos (10mm de diâmetro X 2mm de espessura) de resina composta (FiltekZ250) foram preparados e polidos após 24 horas. A cor inicial e a rugosidade superficial inicial foram mensuradas e os espécimes foram divididos aleatoriamente em quatro grupos (vinho tinto, refrigerante, aguardente, ou saliva artificial - controle) e três subgrupos (sem escovação; escovação com Colgate, ou escovação com Close Up Whitening). Os espécimes foram imersos na sua respectiva solução, $5 x$ ao dia, por 5 minutos, durante 30 dias, sendo dois subgrupos escovados ao final de cada dia (120 movimentos/dia). A cor foi mensurada no $15^{\circ}$ e no $30^{\circ}$ dia de imersão; a rugosidade superficial final foi medida no $30^{\circ}$ dia. Após o período de imersão, os espécimes foram armazenados em saliva artificial por 7 dias, quando a superfície dos mesmos foi polida e imediatamente realizou-se uma mensuração de cor. A alteração de cor foi mensurada com um espectrocolorímetro e analisada pelos valores de $\Delta \mathrm{E}$, $\Delta \mathrm{L}, \Delta \mathrm{a}$, e $\Delta \mathrm{b}$. Os valores de rugosidade (Ra- $\mu \mathrm{m})$ foram medidos com um rugosímetro. Com relação à microdureza, os espécimes primeiramente foram incluídos em resina de poliéster e seccionados no sentido transversal. Após o polimento destas superfícies, foram realizadas mensurações nas profundidades de $30 \mu \mathrm{m}, 60 \mu \mathrm{m}, 90 \mu \mathrm{m}, 120 \mu \mathrm{m}$ e $250 \mu \mathrm{m}$, empregando os parâmetros 25gf/40s de microdureza Knoop. Os dados foram submetidos à ANOVA e teste de Fisher's $(\alpha=5 \%)$. Resultados: Os valores de alteração de cor foram estatisticamente diferentes após a imersão nas bebidas; o vinho tinto promoveu a maior alteração, seguido pelo refrigerante e aguardente, que foram similares entre si e diferentes da saliva artificial. 
Nenhuma diferença foi observada com ou sem escovação, independentemente do dentifrício utilizado. Ao $30^{\circ}$ dia, os espécimes apresentaram uma mudança de cor mais intensa do que ao $15^{\circ}$ dia, após o repolimento, a cor dos espécimes foi similar à cor do $15^{\circ}$ dia. As bebidas e a escovação influenciaram negativamente na rugosidade da superfície. Em relação à microdureza, não houve diferença significativa entre os grupos, independentemente da profundidade analisada. Conclusões: A mudança de cor da resina composta foi influenciada apenas pelas bebidas; a escovação não afetou a propriedade analisada. O repolimento não foi suficiente para promover o retorno da cor dos espécimes aos valores iniciais. A rugosidade superficial foi influenciada negativamente tanto pelas bebidas quanto pela escovação. Para a microdureza, a resina composta apresentou resultados similares independentemente das bebidas utilizadas e da presença ou ausência de escovação nos espécimes avaliados.

Palavras-chave: Resina composta; propriedades físicas; soluções; escovação. 
Lepri CP. Influence of beverages and brushing on the physical properties of a composite resin. [Dissertação de Mestrado]. Ribeirão Preto: Faculdade de Odontologia de Ribeirão Preto da Universidade de São Paulo; 2008.

\section{ABSTRACT}

Objective: This study evaluated the influence of beverages and brushing on the color change, surface roughness and microhardness in depth of a composite resin. Methods: 120 composite resin disks (10mm- $\varnothing \mathrm{X} 2 \mathrm{~mm}$-thickness; Filtek-Z250) were prepared and polished after $24 \mathrm{~h}$. Initials color and surface roughness were measured and specimens were randomly assigned into four groups (red wine, soft drink, sugar cane spirit, or artificial saliva - control) and three subgroups (without brushing; brushing with Colgate, or brushing with Close Up Xtra Whitening). Specimens were immersed in the beverage $5 \mathrm{x} /$ day, for 5 minutes, over 30 days, being two subgroups brushed at the end of every day (120 moving/day). Color was measured at the 15th and 30th days of immersion; final surface roughness was measured at the 30th day. After the immersion period, specimens were stored in artificial saliva for 7 days, when their surfaces were repolished and immediately assessed by color. Color change was measured with a spectrocolorimeter and analyzed by $\Delta \mathrm{E}, \Delta \mathrm{L}, \Delta \mathrm{a}$, and $\Delta \mathrm{b}$ values. The values of roughness $(\mathrm{Ra}-\mu \mathrm{m})$ were measured with a rugosimeter. As regard microhardness, the specimens were firstly included in polyester resin and sectioned in the transverse direction. After polishing these surfaces, measurements were realized at depths of $30 \mu \mathrm{m}, 60 \mu \mathrm{m}, 90 \mu \mathrm{m}$, $120 \mu \mathrm{m}$ and $250 \mu \mathrm{m}$, employing the parameters $25 \mathrm{gf} / 40 \mathrm{~s}$ of microhardness Knoop. Data were submitted to ANOVA and Fisher's tests $(\alpha=5 \%)$. Results: Color change values were statistically different after immersion in the beverages; red wine promoted the highest alteration, followed by soft drink and sugar cane spirit, which presented similar results among them and different from saliva. No difference was observed with or without brushing independently of the toothpaste used. At 30th day, specimens exhibited a color change higher 
than 15th day; after repolishing, the color of the specimens was similar to 15 th day. Beverages and brushing negatively influenced the surface roughness. In relation to microhardness, there was no significant difference among groups, regardless of the depth examined. Conclusions: Color change of the composite resin was influenced only by the beverages and brushing did not affect the analyzed property. The repolishing was not sufficient to promote the return of the specimens' color to their initial values. The surface roughness was negatively influenced both by the beverage as brushing. For microhardness, the composite resin showed similar results regardless of the beverages used and the presence or absence of brushing in the specimens tested.

Keywords: Composite resin; physical properties; beverages; brushing. 
1. Introdução 


\section{INTRODUÇÃO}

Atualmente, as restaurações de resina composta constituem uma parcela significativa da prática rotineira dos dentistas devido à grande demanda dos pacientes por uma aparência estética, $^{3,80,135}$ e isto é possível em virtude do rápido desenvolvimento de novos materiais restauradores, permitindo o seu uso tanto em dentes anteriores quanto posteriores. ${ }^{35,54,80}$ No entanto, o fracasso ou o sucesso de qualquer restauração estética depende da escolha do material, assim como da estabilidade de cor e das propriedades físico-químicas do mesmo. ${ }^{1}$

As primeiras resinas compostas lançadas no mercado caracterizavam-se por um processo de polimerização química e, de modo geral, constituíam-se de um pó ou líquido ou um sistema pasta-pasta, que precisavam ser misturados para o processo de polimerização acontecer. ${ }^{4}$ A polimerização química das resinas foi substituída posteriormente pelos sistemas polimerizados por luz ultravioleta. Devido às vantagens, como o controle total do tempo e menor inclusão de ar dentro da massa da restauração, estes sistemas se tornaram amplamente aceitos pelos profissionais. No entanto, a baixa profundidade de polimerização da luz ultravioleta, associada com os riscos causados aos tecidos vivos por este tipo de radiação, levaram à substituição desse sistema por resinas polimerizadas por luz visível, que predominam no mercado até hoje. ${ }^{27,114}$

Em relação à composição, a estrutura da resina composta e as características das partículas de carga têm impacto direto sobre a lisura superficial e susceptibilidade ao manchamento extrínseco, ${ }^{55,110,117,123}$ bem como os procedimentos de acabamento e polimento podem influenciar a qualidade da superfície dos compósitos.

A composição da matriz da resina desempenha um papel importante na lisura final da restauração, ${ }^{96}$ pois está correlacionada com o fator crítico na estabilidade de cor, ${ }^{30}$ e é afetada 
por diferentes pH das soluções ${ }^{1,126}$ e pela concentração alcoólica. ${ }^{36,39}$ A presença de álcool nas soluções pode favorecer a plastificação da matriz da resina, tornando-a mais macia e propensa à degradação no meio bucal.

Da mesma forma, as partículas de carga (tipo, tamanho e quantidade) influenciam a pigmentação extrínseca do material, pois também podem afetar a rugosidade superficial; assim, resinas de micro-partículas apresentam-se com superfícies mais lisas do que resinas compostas híbridas.

Estes fatores estão relacionados com o início da descoloração deste material. ${ }^{48,110} \mathrm{~A}$ matriz e as partículas de carga não se desgastam com o mesmo grau devido a diferentes propriedades físicas, podendo inclusive ocorrer a desagregação das partículas de quartzo rígido após o polimento e, como conseqüência, o aparecimento de irregularidades na superfície das restaurações. ${ }^{96}$ A rugosidade da superfície causada pelo desgaste e degradação química afeta o brilho e favorece o acúmulo de pigmentos sobre a superfície. ${ }^{122}$

Porém, para garantir adequadas propriedades físico-químicas, é necessária a adequada polimerização das resinas compostas, isto é, as propriedades não dependem apenas da química do material e do tamanho das partículas de carga, mas também do grau de conversão da resina pelas unidades de fotopolimerização, incluindo a sua distribuição espectral, o tempo e a intensidade da exposição. ${ }^{8,51}$ Após a polimerização da resina composta, um movimento de água para dentro (absorção) provoca mobilização dos íons dentro da matriz e um movimento para fora (adsorção) provoca lixiviação de monômeros não reagidos, dos íons (das partículas de carga) e dos ativadores. Esta sorção de água pode causar a degradação da resina, redução da resistência ao manchamento e mudanças na translucidez..$^{30,84,112}$ A solubilidade e a sorção de água das resinas compostas podem ser afetadas pela quantidade de cargas presentes no interior da matriz orgânica. ${ }^{90}$ 
No entanto, o meio bucal é o maior responsável pela degradação química das resinas compostas, independentemente da presença de forças abrasivas e de compressão na cavidade bucal, ${ }^{71,100,122}$ pois a presença de biofilme dental favorece o manchamento superficial do material restaurador, em função da produção de ácidos orgânicos. Esses ácidos promovem maior susceptibilidade ao amolecimento ${ }^{5}$ e alteração da textura superficial da restauração e, conseqüentemente, facilitam o acúmulo de pigmentos extrínsecos. ${ }^{5,69}$ Somado a isso, a saliva humana contém colesterol esterase e hidrolases ativas como, por exemplo, a pseudocolinesterase, e ambos agem sinergicamente, aumentando a biodegradação das resinas compostas. ${ }^{11,41,42,102} \mathrm{Na}$ saliva, também há mucina e glicoproteínas, que formam a película adquirida e favorecem a colonização bacteriana sobre a superfície dental. ${ }^{50}$

Os compósitos atuais apresentam resistência adequada, excelente estética, custo moderado em comparação com as coroas cerâmicas e capacidade de adesão à estrutura dentária. Contudo, a estabilidade de cor ainda é um problema para restaurações estéticas de resina composta, ${ }^{121,129}$ aparecendo como o principal aspecto clínico que leva os pacientes a desejarem a substituição destas restaurações. ${ }^{3,80,135}$

A resistência ao manchamento de um material restaurador na cavidade bucal é importante porque se espera que a reabilitação mantenha a sua aparência natural com os dentes adjacentes durante toda a vida útil..$^{73,108,118}$ Mudança de cor de materiais restauradores estéticos tem sido atribuída a uma ampla variedade de possíveis causas, tais como desgaste, degradação química, oxidação das ligações duplas de carbono não reagidas, acúmulo de pigmentos, desidratação, sorção de água, infiltração, rugosidade superficial e fraca adesão. ${ }^{2,91}$

A descoloração externa pode ser o resultado de hábitos da dieta e de fumar, má higiene bucal e de adsorção ou absorção de manchas solúveis em água em toda a matriz da resina. ${ }^{5,13,86}$ A composição e tamanho das partículas de carga afetam a lisura superficial e a 
susceptibilidade ao manchamento extrínseco. ${ }^{95}$ Fatores intrínsecos, como a matriz da resina ${ }^{58,60}$ e polimerização incompleta, ${ }^{62,63}$ têm uma influência considerável na estabilidade de cor. Isto é geralmente atribuível à degradação química do agente de união e à solubilidade da matriz resinosa. ${ }^{2,58}$

Estudos anteriores ${ }^{13,47}$ relativos à estabilidade de cor têm mostrado que bebidas (como café, chá, vinho tinto, e refrigerantes) e enxagüatórios bucais possuem diferentes graus de manchamento sobre as resinas compostas. O potencial de manchamento destas bebidas e soluções varia de acordo com sua composição e propriedades. ${ }^{16,118,120}$

Para a determinação da cor e do possível manchamento ocorrido, tecnologias instrumentais que quantificam cor e diferença de cor são muito usadas em Odontologia. A medição de cor instrumental de materiais translúcidos é influenciada pelas propriedades do fundo. Quando a luz ilumina um espécime translúcido apoiado em um fundo brilhante/branco, muita fração da luz que atingiu o fundo pode ser refletida, no entanto, quando apoiada em um fundo preto, o grau de reflexão pode ser reduzido significativamente, ${ }^{75}$ sendo importante identificar o fundo nos casos de cor de espécimes sólidos. ${ }^{10}$

Atualmente, existem diferentes metodologias e equipamentos para análise de cor, tornando possível estudar inúmeros parâmetros relacionados com a estabilidade de cor da resina composta. Dentre eles, têm-se a espectrofotometria e a colorimetria, aplicada em testes in vitro e in vivo..$^{7,40,101,105,120} \mathrm{O}$ sistema empregado nestes equipamentos normalmente é baseado no sistema CIELab. ${ }^{25}$ No entanto, há várias discussões sobre os parâmetros das diferenças de cores perceptíveis ou aceitáveis em restaurações estéticas. ${ }^{64,101,108}$

O sistema CIELab corresponde a um sistema de coordenadas, onde o valor de L* é a medida de luminosidade de um objeto e é quantificado com uma escala que varia do preto (zero) ao branco (100). Os valores de $\mathrm{a}^{*}$ e b* são medidas de cromaticidade, onde $\mathrm{a}^{*}$ designa 
o eixo verde-vermelho. Isso significa que, quando o valor for negativo mostrará desvio para tonalidade verde e quando for positivo mostrará o desvio no sentido do vermelho. $\mathrm{O}$ valor $\mathrm{b}^{*}$ denomina o eixo azul-amarelo e quando este apresentar valor negativo o desvio será no sentido da tonalidade azul e quando for positivo mostrará o desvio no sentido do amarelo. A diferença de cor é obtida pelo cálculo $\Delta \mathrm{Eab}^{*}=\left[\left(\Delta \mathrm{L}^{*}\right)^{2}+\left(\Delta \mathrm{a}^{*}\right)^{2}+\left(\Delta \mathrm{b}^{*}\right)^{2}\right]^{1 / 2}$.

A resistência aos efeitos do manchamento causado pelas soluções, tais como café, chá e suco são medidos com um espectrofotômetro e são expressas em unidades de $\Delta \mathrm{E}^{*}$, com os valores mais baixos indicando uma menor coloração. $\mathrm{O}$ valor de $\Delta \mathrm{E}^{*}$ representa a mudança de cor relativa que um observador poderia relatar para os materiais após o tratamento, ou entre os períodos. No entanto, existe certa confusão sobre o valor aceitável de $\Delta \mathrm{E}^{*}$. O olho humano não pode normalmente detectar valores de $\Delta \mathrm{E}^{*}<1,5$, embora este valor seja mensurável através de um espectrocolorímetro.

Diversos estudos relataram diferentes limiares de $\Delta \mathrm{E}$, sendo igual a $1,{ }^{108,109}$ maior ou igual a $3,3^{60,70,72,115}$ e maior ou igual a $3,7 .{ }^{64}$ Alguns estudos consideram que valores de $\Delta \mathrm{E}$ no intervalo de 2 a 3 são perceptíveis, valores entre 3 a 8 são moderadamente perceptíveis, e valores acima de 8 totalmente inaceitáveis. ${ }^{46}$ Seghi, Hewlett e Kim ${ }^{108}$ (1989) também presumiram que uma diferença de cor aceitável poderia ser freqüentemente duas ou três vezes maior do que os limites detectáveis. ${ }^{108} \mathrm{O}$ limite máximo de aceitabilidade em avaliações visuais subjetivas tem sido confirmado por Ruyter, Nilner e Moller ${ }^{101}$ (1987); Um e Ruyter ${ }^{120}$ (1991), que sugeriram que a diferença de cor é aceitável até o valor $\Delta \mathrm{E}^{*}=3,3$. A classificação alfa de acordo com o sistema de avaliação clínica das restaurações estéticas do Serviço Público de Saúde dos Estados Unidos mostrou que os valores de $\Delta \mathrm{E}^{*}$ clinicamente aceitáveis variam entre 2,2 e $4,4 .^{64}$ 
Uma vez que o manchamento ocorreu, a escovação com dentifrício, o repolimento e os procedimentos de clareamento podem remover as manchas, parcialmente ou totalmente. Os procedimentos de polimento, embora removam materiais da superfície dos compósitos, podem corrigir compósitos altamente manchados. ${ }^{14,26,28,47,57,82,83,97} \mathrm{O}$ acabamento superficial de compósitos com uma tira matriz de celulóide pode produzir a superfície mais lisa possível, porém mais susceptível ao manchamento. ${ }^{48}$ Portanto, é recomendado o acabamento e polimento destas restaurações, apesar do bom acabamento conseguido com a matriz de celulóide, ${ }^{125,128}$ mas no seu devido tempo, pois o acabamento e polimento precoces resultam em maior susceptibilidade ao manchamento. ${ }^{24}$

Enquanto estudos ${ }^{30,48,104}$ demonstraram que a rugosidade superficial das resinas compostas tem uma influência direta sobre a susceptibilidade ao manchamento, outros ${ }^{95,110}$ têm relatado nenhuma correlação entre a rugosidade superficial e a suscetibilidade ao manchamento. A rugosidade superficial da resina composta normalmente é ditada em função do tamanho, dureza e quantidade das partículas de carga, que influenciam as propriedades mecânicas das resinas compostas, pela flexibilidade do material de apoio, dureza e tamanho do abrasivo. ${ }^{96,133}$

Outra propriedade importante das resinas compostas é a microdureza, pois esta determina a capacidade de deformação do material restaurador ${ }^{132}$ e permite sua comparação ao esmalte e à dentina, a fim de se encontrar materiais com propriedades similares às da estrutura dental. ${ }^{127}$ Os valores desta grandeza, além de permitirem a avaliação da capacidade de polimerização do compósito, têm sido freqüentemente usados para definir a resistência do material ao desgaste.

No entanto, não foram realizados estudos in vitro associando imersão em bebidas com a escovação sobre as propriedades físicas das resinas compostas, sendo necessários mais 
estudos para avaliar se a estabilidade de cor da resina composta, assim como a rugosidade superficial e a microdureza em profundidade podem ser influenciadas pela imersão em soluções associada com a escovação. 


$$
\text { - }
$$




\section{PROPOSIÇÃO}

Este trabalho in vitro teve por objetivo avaliar quantitativamente a influência de bebidas e escovação na estabilidade de cor, rugosidade superficial e microdureza em profundidade de uma resina composta. 


\section{MATERIAIS E MÉTODOS}

\subsection{Delineamento experimental}

Os fatores em estudo foram: soluções em quatro níveis (vinho tinto, refrigerante, aguardente e saliva artificial-controle) e escovação em três níveis: um controle (sem escovação-GA) e dois experimentais (escovação com Colgate-GB; escovação com Close-Up Xtra Whitening-GC). A amostra do experimento teve 120 corpos-de-prova de resina composta Z250 divididos em 12 grupos/subgrupos (pela combinação dos níveis dos fatores soluções e escovação).

Este estudo foi realizado por meio de um delineamento em blocos completos casualizados, com uma repetição de cada grupo experimental por bloco. As variáveis de resposta quantitativa foram: estabilidade de cor $(\Delta \mathrm{E}, \Delta \mathrm{L}, \Delta \mathrm{a}$ e $\Delta \mathrm{b})$, rugosidade superficial $(\mu \mathrm{m})$ e microdureza $(\mathrm{HK})$ em profundidade. Para a resposta quantitativa de estabilidade de cor, foi acrescentado o fator tempo em 3 níveis: 15 dias, 30 dias e após repolimento.

\subsection{Confecção dos corpos-de-prova}

A resina composta (Tabela 1) foi manipulada seguindo as instruções do fabricante e inserida dentro de uma matriz metálica de aço inoxidável cilíndrica $(10 \mathrm{~mm}$ de diâmetro $\mathrm{X}$ $2 \mathrm{~mm}$ de espessura/altura), realizando inserção em único incremento.

Imediatamente após a inserção do material, a matriz foi coberta com uma lâmina de vidro, sobre a qual foi aplicada uma carga axial de 500g, durante 1 minuto, para compactar a resina composta, tornando a superfície plana e com espessura padronizada. 
Após a remoção da carga, procedeu-se à fotopolimerização (Jetlite 4000 - J Morita USA Inc. - Irvine - CA - 92618 - USA) do material através da lâmina de vidro por meio de luz visível, por 20 segundos. A intensidade de luz visível foi monitorada através de um radiômetro e situou-se por volta de $900 \mathrm{~mW} / \mathrm{cm}^{2}$. Após a confecção dos espécimes, estes foram mantidos em saliva artificial e armazenados em estufa a $37^{\circ} \mathrm{C}\left( \pm 1^{\circ} \mathrm{C}\right)$.

Tabela 1. Resina composta testada no presente estudo.

\begin{tabular}{|c|c|c|c|c|c|c|}
\hline $\begin{array}{l}\text { Compósito } \\
\text { (Cor) }\end{array}$ & $\begin{array}{l}\text { Composição da } \\
\text { matriz da } \\
\text { resina (Carga)* }\end{array}$ & $\begin{array}{c}\text { Tamanho } \\
\text { médio das } \\
\text { partículas de } \\
\text { carga }\end{array}$ & $\begin{array}{c}\text { Porcentagem } \\
\text { de carga }\end{array}$ & $\begin{array}{c}\text { Tempo de } \\
\text { foto- } \\
\text { polimerização }\end{array}$ & Fabricante & Lote \\
\hline $\begin{array}{c}\text { Filtek Z250 } \\
\text { (A3) }\end{array}$ & $\begin{array}{c}\text { Bis-GMA, } \\
\text { UDMA, e Bis- } \\
\text { EMA } \\
\text { (zircônia/sílica) }\end{array}$ & $\begin{array}{c}0,01-3,5 \mu \mathrm{m} \\
\text { com um } \\
\text { tamanho } \\
\text { médio de } \\
\text { partícula de } \\
0,6 \mu \mathrm{m}\end{array}$ & $\begin{array}{c}82 \% \text { peso } \\
\text { (60\% volume) }\end{array}$ & 20 segundos & $\begin{array}{c}\text { 3M ESPE. St. } \\
\text { Paul - MN - } \\
55144-1000- \\
\text { USA }\end{array}$ & $6 \mathrm{BN}$ \\
\hline
\end{tabular}

*Bis-GMA = bisfenol-A-glicidil-dimetacrilato; UDMA = uretana-dimetacrilato; Bis-EMA = bisfenol-A-polietilenoglicol-diéterdimetacrilato. *Informação das instruções do fabricante.

\subsection{Acabamento e polimento dos corpos-de-prova}

Após 24 horas, as unidades experimentais foram submetidas ao acabamento com discos Super-Snap (granulação média e fina) (Shofu Inc. Kyoto - 605-0983 - Japan). Após serem lixados, os corpos-de-prova foram polidos com discos de feltro e pasta diamantada (KG Sorensen Ind. e Com. Ltda. - Barueri - SP - 06465-130 - Brasil) com granulação de $6 \mu \mathrm{m}$ e $3 \mu \mathrm{m}$. Ao final desses procedimentos, os espécimes foram lavados com água destilada por 30 segundos, secos com papel absorvente e mergulhados em saliva artificial por mais 24 horas em estufa a $37^{\circ} \mathrm{C}$ para então realizar as mensurações iniciais de rugosidade e de cor e em seguida iniciar o ciclo de solução/escovação (Figura 1). 


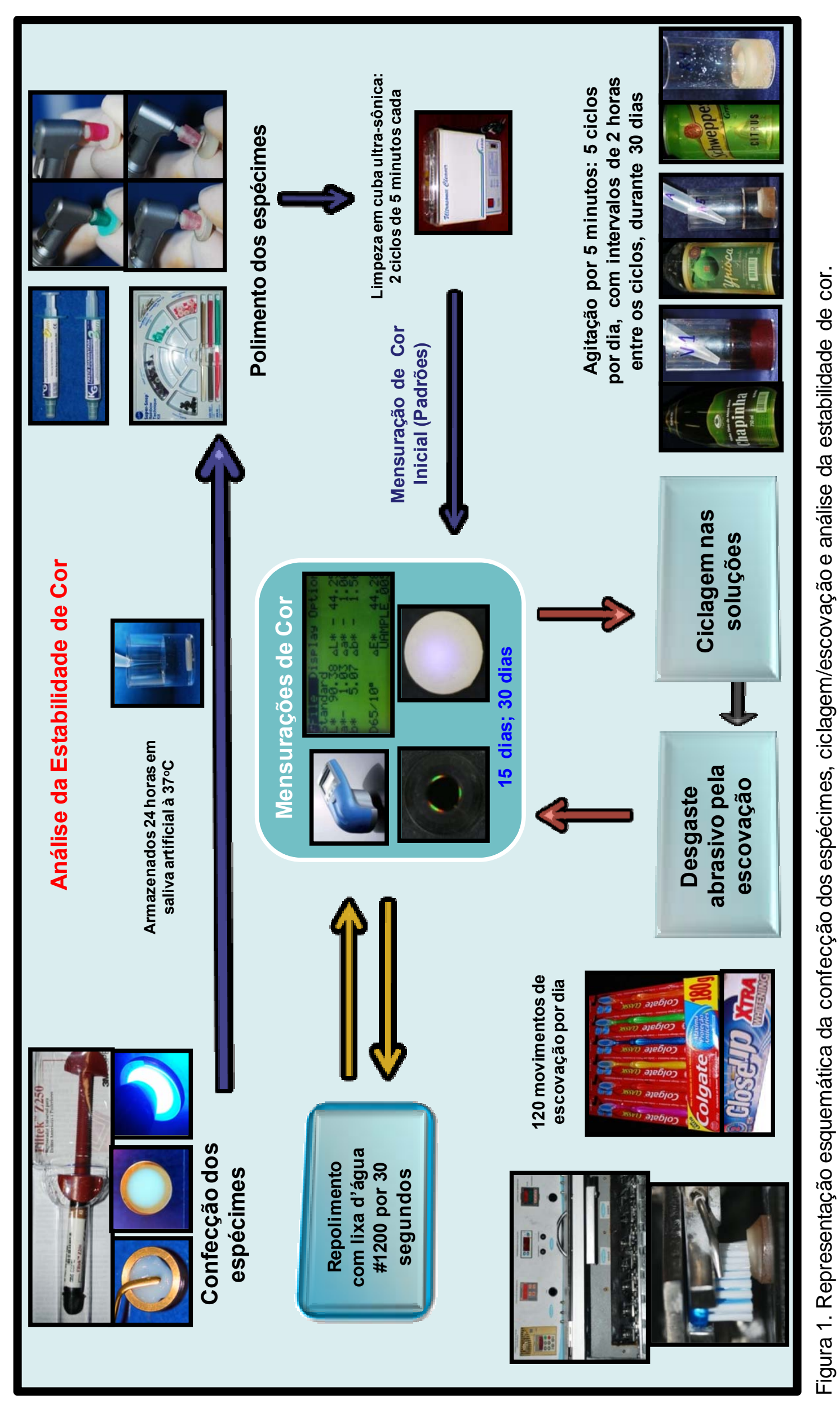




\subsection{Avaliação da rugosidade superficial inicial (Ri)}

Os espécimes foram avaliados quanto ao seu padrão de rugosidade superficial por meio do rugosímetro Surfcorder SE1700 (Kosaka Laboratory Ltd. Tokyo - 101-0021 Japan). A ponta sensora de $2 \mu \mathrm{m}$ de diâmetro, exercendo pressão de contato de $0,7 \mathrm{mN}$, realizou traçados a uma velocidade de $0,5 \mathrm{~mm} / \mathrm{s}$, totalizando 12 leituras por corpo-de-prova, 4 no sentido da escovação e 8 perpendiculares a este sentido. O comprimento de amostragem ou cut-off empregado foi $0,08 \mathrm{~mm}$. Foram realizadas mensurações através do parâmetro que se baseia em medida vertical $(\mathrm{Ra} / \mu \mathrm{m})$ da rugosidade superficial. A média das 12 leituras foi utilizada como a medida de cada espécime, previamente à realização dos ensaios de escovação, considerada rugosidade inicial (Ri).

\subsection{Análise da cor inicial}

Antes do início da ciclagem foi analisada a cor inicial dos espécimes de acordo com o sistema CIELab, com iluminação padrão D65 sobre fundo branco com o espectrofotômetro de colorimetria (Color guide 45/0, PCB 6807 BYK-Gardner GmbH. Gerestsried - 82538 Germany). O padrão de cada espécime foi medido examinando as coordenadas $L^{*}, a^{*}$ e b* do sistema CIELab.

Antes de cada leitura, os espécimes foram lavados com água destilada por um minuto e secos com papel absorvente. 


\subsection{Ciclagem nas soluções}

Primeiramente, para que apenas a "superfície externa" da resina composta (lado que foi fotopolimerizado) entrasse em contato com as soluções, os espécimes foram fixados com parafina em cilindros confeccionados com resina de poliéster.

Os corpos-de-prova foram então divididos aleatoriamente em quatro grupos: o grupo controle foi mantido em saliva artificial e os três grupos experimentais foram submetidos à ciclagem nas bebidas selecionadas (vinho tinto, refrigerante e aguardente) (Tabela 2).

Tabela 2. Soluções empregadas no presente estudo.

\begin{tabular}{|c|c|c|c|c|c|}
\hline $\begin{array}{c}\text { Solução } \\
\text { (Nome } \\
\text { Comercial) }\end{array}$ & Composição & $\begin{array}{c}\text { Teor } \\
\text { Alcoólico }\end{array}$ & $\mathbf{p H}$ & Fabricante & Lote \\
\hline $\begin{array}{l}\text { Saliva } \\
\text { Artificial }\end{array}$ & $\begin{array}{l}\mathrm{KH} 2 \mathrm{PO} 4, \mathrm{~K} 2 \mathrm{HPO} 4, \mathrm{KCl}, \mathrm{NaCl}, \\
\mathrm{MgCl} 2.6 \mathrm{H} 2 \mathrm{O}, \mathrm{CaCl} 2.2 \mathrm{H} 2 \mathrm{O}, \mathrm{NaF} \text {, } \\
\text { Sorbitol, Nipagin, Nipasol, } \\
\text { Carboximetilcelulose (CMC), água. }\end{array}$ & - & 7,00 & $\begin{array}{l}\text { Laboratório de } \\
\text { Bioquímica da } \\
\text { FCFRP-USP }\end{array}$ & - \\
\hline $\begin{array}{l}\text { Ypióca } \\
\text { Limão } \mathbb{R}\end{array}$ & $\begin{array}{l}\text { Cachaça, água, açúcar, suco de limão e } \\
\text { óleo essencial de limão. }\end{array}$ & $30 \%$ Vol. & 3,53 & $\begin{array}{c}\text { Ypióca } \\
\text { Agroindustrial } \\
\text { Ltda. Fortaleza - } \\
\text { CE - 60841-030 } \\
\text { - Brasil. }\end{array}$ & 010 \\
\hline $\begin{array}{c}\text { Vinho } \\
\text { Chapinha } \mathbb{R}\end{array}$ & $\begin{array}{l}\text { Vinho Tinto de Mesa Seco, conservantes } \\
\text { INS } 200 \text { e INS } 224 \text { e acidulante INS } 330 . \\
\text { Não contém glúten. }\end{array}$ & $\begin{array}{l}10,7 \% \\
\text { Vol. }\end{array}$ & 3,19 & $\begin{array}{l}\text { Passarin Ind. e } \\
\text { Com. De } \\
\text { Bebidas Ltda. } \\
\text { Jundiaí - SP - } \\
\text { 13216-351 - } \\
\text { Brasil. }\end{array}$ & $154 / 07$ \\
\hline $\begin{array}{l}\text { Schweppes } \\
\text { Citrus } \AA\end{array}$ & $\begin{array}{c}\text { Água gaseificada, açúcar, sucos naturais } \\
\text { de maça, laranja e grapefruit } 5 \%, \\
\text { acidulante INS } 330 \text {, aroma natural, } \\
\text { conservador INS } 211 \text {, estabilizantes INS } \\
414 \text { e INS 445ii, corante artificial } \\
\text { tartrazina. }\end{array}$ & - & 2,75 & $\begin{array}{l}\text { Cia. de Bebidas } \\
\text { Ipiranga. } \\
\text { Ribeirão Preto - } \\
\text { SP - } 14055-630 \\
\text { - Brasil. }\end{array}$ & P071007 \\
\hline
\end{tabular}


Os espécimes foram mantidos imersos em saliva artificial a $37^{\circ} \mathrm{C} \pm 1{ }^{\circ} \mathrm{C}$ no intervalo entre os ciclos. As bebidas foram empregadas na temperatura de consumo, ou seja, refrigerante $\pm 4^{\circ} \mathrm{C}$, vinho tinto $\pm 25^{\circ} \mathrm{C}$ e aguardente $\pm 25^{\circ} \mathrm{C}$. As temperaturas foram medidas com termômetro digital.

Os espécimes foram mergulhados nas respectivas soluções $(20 \mathrm{~mL} / \mathrm{espécime})$ por cinco minutos em agitação ${ }^{17}$ (Mesa Agitadora Orbital CT-155, Cientec Equipamentos para Laboratórios. Piracicaba - SP - 13426-155 - Brasil), cinco vezes ao dia, com intervalos de 2 horas. Para o grupo controle (espécimes mantidos em saliva artificial), os espécimes foram mantidos a $37^{\circ} \mathrm{C}$ trocando diariamente a saliva. Esses procedimentos foram repetidos por 30 dias.

\subsection{Ensaios de escovação}

Ao final de cada dia, após a ciclagem nas soluções, os corpos-de-prova dos subgrupos escovados foram identificados e receberam uma marcação para o posicionamento sempre na mesma posição na máquina de escovação. Para o grupo controle, os espécimes foram mantidos em saliva artificial à $37^{\circ} \mathrm{C}$.

O desgaste abrasivo foi realizado em uma máquina de escovação (MSEt-Marcelo Nucci-ME, São Carlos, Brasil) que simula a técnica horizontal de escovação. Os corpos-deprova foram posicionados paralelamente às cerdas da escova dental (Colgate Classic, ColgatePalmolive Indústria e Comércio Ltda. - São Bernardo do Campo - SP, 09696-000 Brasil) e sobre eles incidiu-se uma carga de $400 \mathrm{~g}$.

Uma solução (slurry) obtida pela mistura de dentifrício (Tabela 3) e água destilada na proporção de 1:2 em peso, respectivamente, foi injetada lateralmente ao corpo-de-prova, entre 
o material restaurador e a escova dental, durante os movimentos de escovação. Esta solução era preparada todos os dias 20 minutos antes do seu uso.

Foram realizados 120 movimentos de escovação/dia (simulando três escovações com 40 movimentos por dia), com velocidade de 4,5 movimentos/segundo ${ }^{53}$ e amplitude de excursão de $25 \mathrm{~mm}$, a $37^{\circ} \mathrm{C}\left( \pm 0,5^{\circ} \mathrm{C}\right)$.

O mesmo protocolo de aplicação das soluções seguido pelo ensaio de escovação foi repetido por 30 dias.

Tabela 3. Dentifrícios utilizados durante a escovação.

\begin{tabular}{|c|c|c|c|}
\hline $\begin{array}{l}\text { Dentifrício (Nome } \\
\text { Comercial) }\end{array}$ & Composição & Fabricante & Lote \\
\hline $\begin{array}{c}\text { Colgate - Máxima } \\
\text { Proteção Anticáries } \mathbb{}\end{array}$ & $\begin{array}{l}1450 \text { ppm de flúor, carbonato de cálcio, } \\
\text { lauril sulfato de sódio, sacarina sódica, } \\
\text { pirofosfato tetrassódico, silicato de sódio, } \\
\text { sorbitol, carboximetilcelulose, } \\
\text { metilparabeno, propilparabeno, aroma e } \\
\text { água. Contém monofluorfosfato de } \\
\text { sódio-MFP. }\end{array}$ & $\begin{array}{c}\text { Colgate-Palmolive } \\
\text { Indústria e Comércio } \\
\text { Ltda. São Bernardo do } \\
\text { Campo - SP - 09696- } \\
\text { 000 - Brasil. }\end{array}$ & 7141BR123M \\
\hline $\begin{array}{l}\text { Close Up Xtra } \\
\text { Whitening } \AA\end{array}$ & $\begin{array}{l}1500 \text { ppm de flúor, carbonato de cálcio, } \\
\text { água, sorbitol, sílica, lauril sulfato de } \\
\text { sódio, aroma, fosfato trissódico, dióxido } \\
\text { de titânio, goma de celulose, perlite, } \\
\text { sacarina sódica, formaldeído. Contém } \\
\text { monofluorfosfato de sódio -MFP. }\end{array}$ & $\begin{array}{l}\text { IGL Industrial Ltda. - } \\
\text { Vinhedo - SP - 13280- } \\
000 \text { - Brasil (Unilever). }\end{array}$ & 8081 \\
\hline
\end{tabular}

\subsection{Avaliação da rugosidade superficial final (Rf)}

Os espécimes foram avaliados novamente quanto ao seu padrão de rugosidade superficial ao término de 30 dias (Rf). A variável de resposta foi a diferença da rugosidade final menos a inicial (Rf - Ri) (Figura 2). 


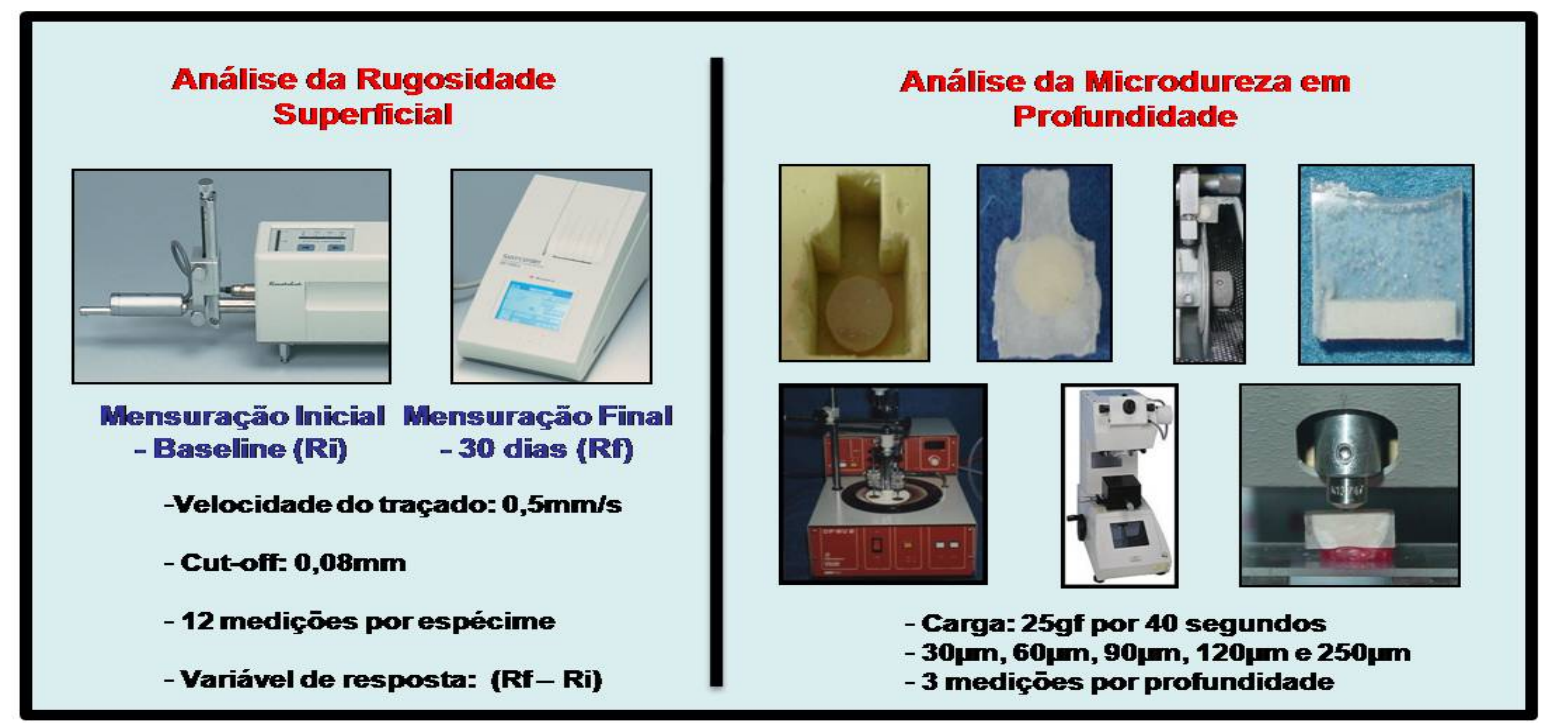

Figura 2. Metodologia empregada para análise de rugosidade superficial e microdureza em profundidade

\subsection{Análise da cor final}

A cor foi medida novamente ao $15^{\circ}$ e $30^{\circ}$ dia de imersão. Após o período de imersão, os espécimes foram armazenados em saliva artificial por 7 dias, quando a superfície deles foi repolida e imediatamente aferiu-se novamente a cor. O repolimento foi realizado com lixa d'água \#1200, através da utilização de um peso fixo de $500 \mathrm{~g}$, por 30 segundos, proporcionando dessa forma um desgaste de aproximadamente $100 \mu \mathrm{m}$. A diferença de cor foi obtida pelo cálculo $\Delta \mathrm{Eab}^{*}=\left[\left(\Delta \mathrm{L}^{*}\right) 2+\left(\Delta \mathrm{a}^{*}\right) 2+\left(\Delta \mathrm{b}^{*}\right) 2\right]^{1 / 2}$. A diferença de luminosidade $(\Delta \mathrm{L}), \Delta \mathrm{a}, \mathrm{e} \Delta \mathrm{b}$ também foram calculadas pela fórmula $\Delta \mathrm{L}^{*}=\mathrm{L}^{*}(\mathrm{t})-\mathrm{L}^{*}(0), \Delta \mathrm{a}^{*}=\mathrm{a}^{*}(\mathrm{t})-\mathrm{a}^{*}$ (0) e $\Delta b^{*}=b^{*}(t)-b^{*}(0)$, onde $(\mathrm{t})$ corresponde ao tempo e (0) corresponde ao baseline. A alteração de cor foi analisada pelos valores de $\Delta \mathrm{E}, \Delta \mathrm{L}, \Delta \mathrm{a}$, e $\Delta \mathrm{b}$ (Figura 1). 


\subsection{Avaliação da microdureza em profundidade}

Após o término das mensurações de cor e rugosidade, os espécimes foram armazenados por 7 dias em saliva artificial. Em seguida, foram incluídos em resina de poliéster e seccionados no sentido transversal. Após o polimento destas superfícies com lixa d'água (carbureto de silício) e disco de feltro com alumina, foram realizadas mensurações (microdurômetro HMV-2000, Shimadzu Corporation, Kyoto, Japan) nas profundidades de $30 \mu \mathrm{m}, 60 \mu \mathrm{m}, 90 \mu \mathrm{m}, 120 \mu \mathrm{m}$ e $250 \mu \mathrm{m}$, sendo três marcações em cada profundidade, uma central e as outras deslocadas $500 \mu \mathrm{m}$ à direita e à esquerda, exercendo uma carga de $25 \mathrm{gf}$ por 40s. Os valores em HK foram empregados para análise dos dados (Figura 2).

\subsection{Análise dos dados}

Os dados foram analisados quanto a sua distribuição e homogeneidade, e como se apresentaram normais (Shapiro-Wilks) e homogêneos (Levene's), realizou-se a análise da variância a dois critérios (two-way ANOVA: bebidas; escovação) para todas as propriedades analisadas, sendo que o tempo foi analisado individualmente para a alteração de cor. Para diferenciação das médias, empregou-se o teste de Fisher LSD em nível de significância de $5 \%$. 


\section{RESULTADOS}

\subsection{Estabilidade de Cor}

$\mathrm{Na}$ análise dos dados, observou-se que as soluções promoveram uma alteração estatisticamente significativa $(\mathrm{p}<0,05)$ na cor $(\Delta \mathrm{E})$ dos espécimes, tendo o vinho tinto $(3,88)$ promovido a maior alteração, seguido pelo refrigerante $(2,23)$ e aguardente $(2,09)$, que apresentaram resultados semelhantes entre si e diferentes da saliva $(1,18)$. Para o fator escovação, verificaram-se comportamentos semelhantes para os subgrupos, independentemente do dentifrício (sem escovação - 2,36; Colgate - 2,34 e Close-up - 2,33).

$\mathrm{Na}$ interação dos fatores escovação x soluções, observou-se que a saliva foi que menos promoveu alteração de cor, porém quando se realizou a escovação com o Close-up, ocorreu alteração significativa da propriedade $(\mathrm{p}<0,05)$. Para as soluções aguardente e refrigerante, observou-se comportamentos semelhantes entre os espécimes escovados e não-escovados. No vinho tinto, observou-se que o subgrupo não escovado apresentou estatisticamente $(p<0,05)$ maior alteração de cor que os demais e que os dentifrícios influenciaram na intensidade da alteração, tendo o GB apresentado menor alteração $(\mathrm{p}<0,05)$ (Figura 3). 


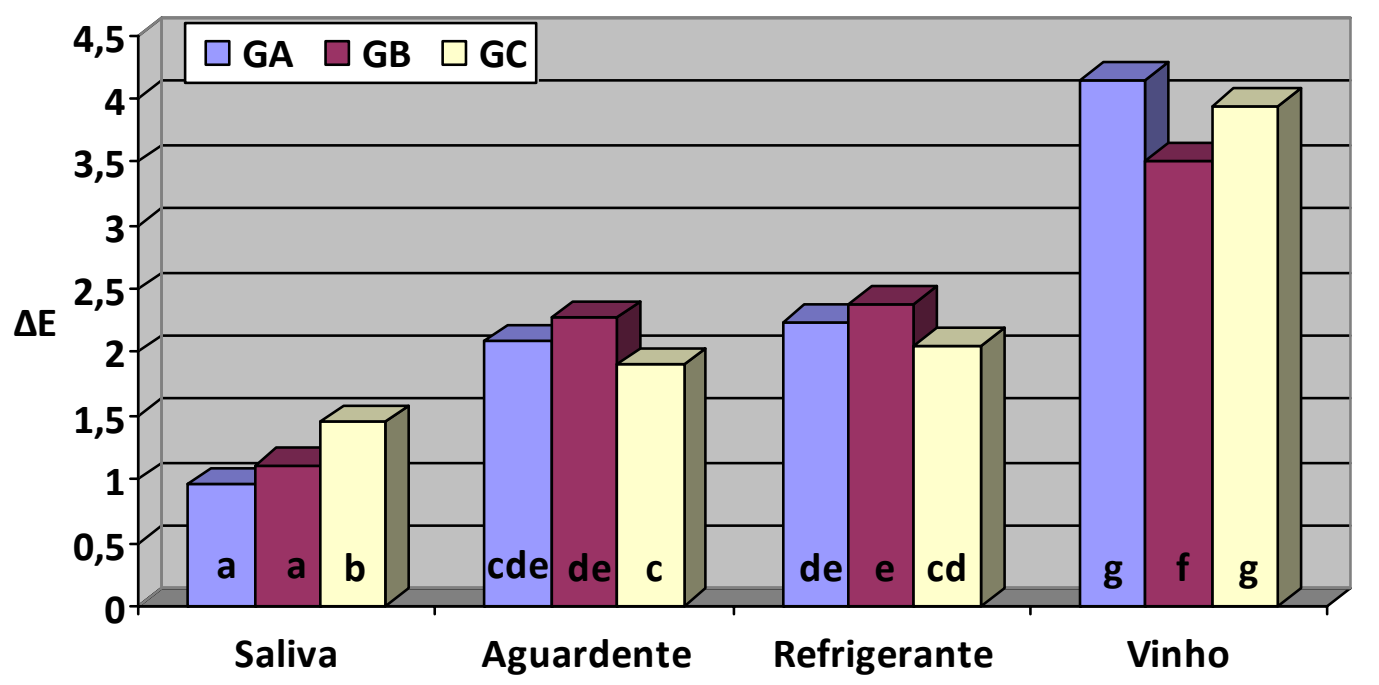

Figura 3. Valores médios do $\Delta \mathrm{E}$ na interação dos fatores escovação x soluções (Mesma letra representa similaridade estatística).

Em relação ao tempo, pode-se observar que a saliva apresentou as menores alterações e estatisticamente significante em relação aos demais subgrupos. O repolimento promoveu uma cor mais intensa e estatisticamente significante $(\mathrm{p}<0,05)$ nos espécimes das soluções aguardente, refrigerante e saliva em relação a 30 dias de imersão. Contudo, para o vinho tinto, o repolimento promoveu uma melhora acentuada na cor e foi diferente estatisticamente em relação ao $15^{\circ}$ e $30^{\circ}$ dia (Figura 4). No geral, observou-se que ao $30^{\circ}$ dia $(2,76)$ os espécimes exibiram uma maior alteração de cor do que ao $15^{\circ}$ dia $(2,13)(\mathrm{p}<0,05)$; após repolimento $(2,15)$, a cor dos espécimes foi similar ao $15^{\circ}$ dia. 


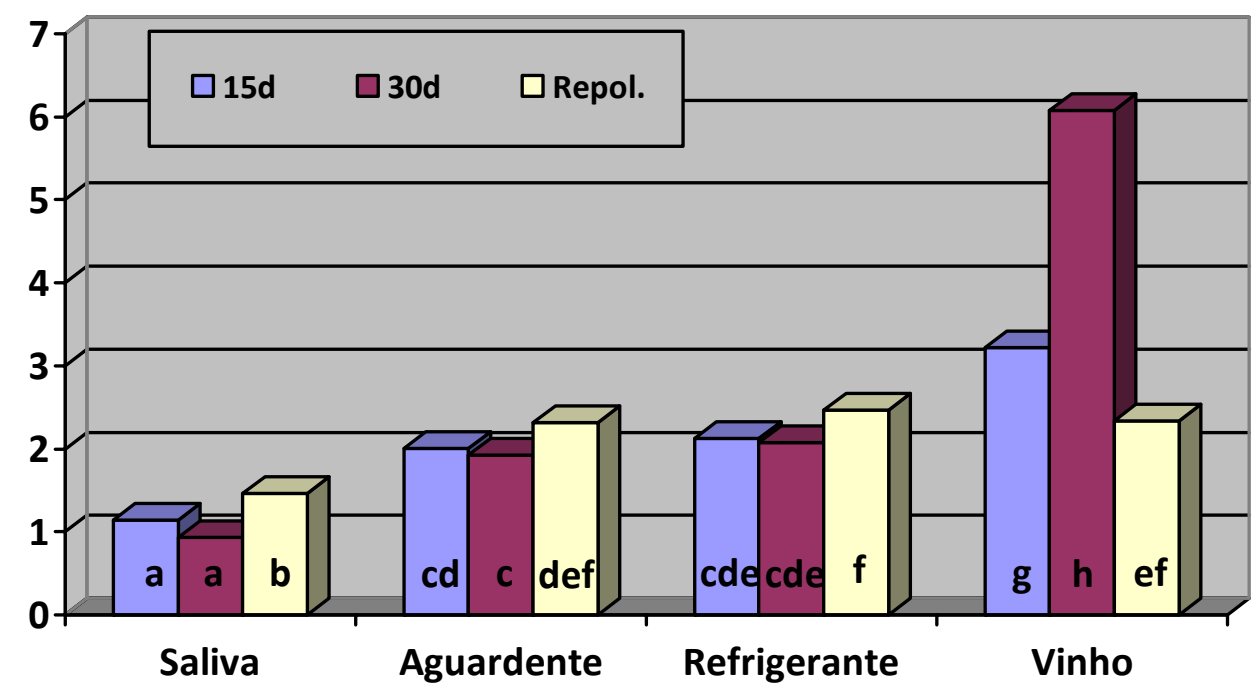

Figura 4. Valores médios do $\Delta \mathrm{E}$ na interação dos fatores soluções $\mathrm{x}$ tempo (Mesma letra representa similaridade estatística).

As médias e os respectivos desvios-padrão dos subgrupos estão descritos na Tabela 4. A representação gráfica do comportamento das soluções/escovação/tempo está na Figura 5.

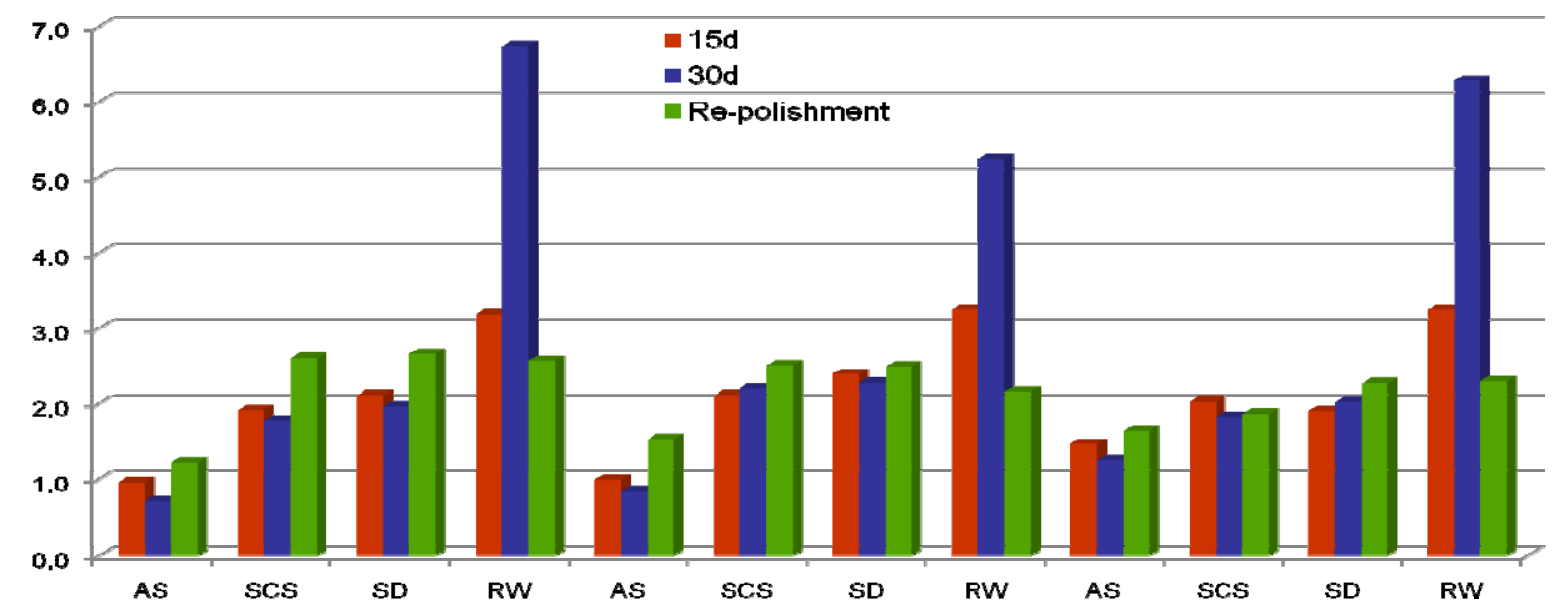

Figura 5. Valores médios de $\Delta \mathrm{E}$ dos subgrupos estudados (*AS = saliva artificial, $\mathrm{SCS}=$ aguardente, $\mathrm{SD}=$ refrigerante, $\mathrm{RW}=$ vinho tinto). 
Tabela 4. Médias $\Delta \mathrm{E}^{*}$ e desvios-padrão dos subgrupos estudados.

\begin{tabular}{ccccc}
\hline \hline Grupos & Subgrupos & $\mathbf{1 5}$ dias & 30 dias & Repolimento \\
\hline \hline \multirow{2}{*}{ Sem Escovação } & Saliva & $0,96 \pm 0,28$ & $0,71 \pm 0,30$ & $1,22 \pm 0,39$ \\
(GA) & Rguardente & $1,91 \pm 0,37$ & $1,77 \pm 0,52$ & $2,60 \pm 0,62$ \\
& Refrigerante & $2,11 \pm 0,61$ & $1,96 \pm 0,54$ & $2,65 \pm 0,53$ \\
& Vinho Tinto & $3,18 \pm 0,54$ & $6,73 \pm 0,78$ & $2,56 \pm 0,53$ \\
Colgate & Saliva & $0,99 \pm 0,36$ & $0,83 \pm 0,41$ & $1,52 \pm 0,51$ \\
(GB) & Aguardente & $2,11 \pm 0,65$ & $2,20 \pm 0,71$ & $2,50 \pm 0,63$ \\
& Refrigerante & $2,39 \pm 0,81$ & $2,27 \pm 0,74$ & $2,49 \pm 0,97$ \\
& Vinho Tinto & $3,24 \pm 0,83$ & $5,23 \pm 0,90$ & $2,16 \pm 0,55$ \\
& Saliva & $1,47 \pm 0,59$ & $1,25 \pm 0,67$ & $1,64 \pm 0,72$ \\
(GC) & Aguardente & $2,02 \pm 0,65$ & $1,82 \pm 0,60$ & $1,86 \pm 0,91$ \\
& Refrigerante & $1,90 \pm 0,49$ & $2,01 \pm 0,33$ & $2,26 \pm 0,56$ \\
& Vinho Tinto & $3,24 \pm 0,42$ & $6,28 \pm 0,48$ & $2,29 \pm 0,56$ \\
\hline \hline
\end{tabular}

Para luminosidade $(\Delta \mathrm{L})$ pode-se observar que a escovação alterou esta propriedade significantemente, tendo o grupo do dentifricio Close-up apresentado a menor alteração $(0,08)$, estatisticamente significante em relação ao Colgate $(0,30)$ e semelhante em relação ao controle $(0,20)$. Em relação às soluções empregadas, observou-se alteração estatisticamente significante, tendo a saliva apresentado menor alteração $(0,84)$ e estatisticamente diferente das demais, seguido da aguardente $(1,16)$ e do refrigerante $(1,18)$, que foram semelhantes entre si.

$\mathrm{Na}$ interação dos fatores observou-se que o vinho tinto promoveu um escurecimento estatisticamente significante em relação aos demais subgrupos, tendo o GC apresentado o maior escurecimento, seguido do GA; o GB apresentou os menores valores. Para as outras soluções, observou-se uma tonalidade ligeiramente mais clara para a saliva, e mais intensa para a aguardente e refrigerante, não tendo diferença entre escovados ou não (Figura 6). Em 
relação ao tempo, observou-se após 30 dias (espécimes não escovados) um tênue escurecimento das amostras, porém um pouco superior ao GB e GC. No repolimento, o GA e GB apresentaram comportamento semelhante entre si, com a tonalidade mais clara que inicialmente, sendo estatisticamente significante em relação ao GC, que se apresentou mais próximo da leitura inicial (Figuras 7 e 8 ). As médias e os respectivos desvios-padrão do $\Delta \mathrm{L}$ dos subgrupos estão descritos na Tabela 5.

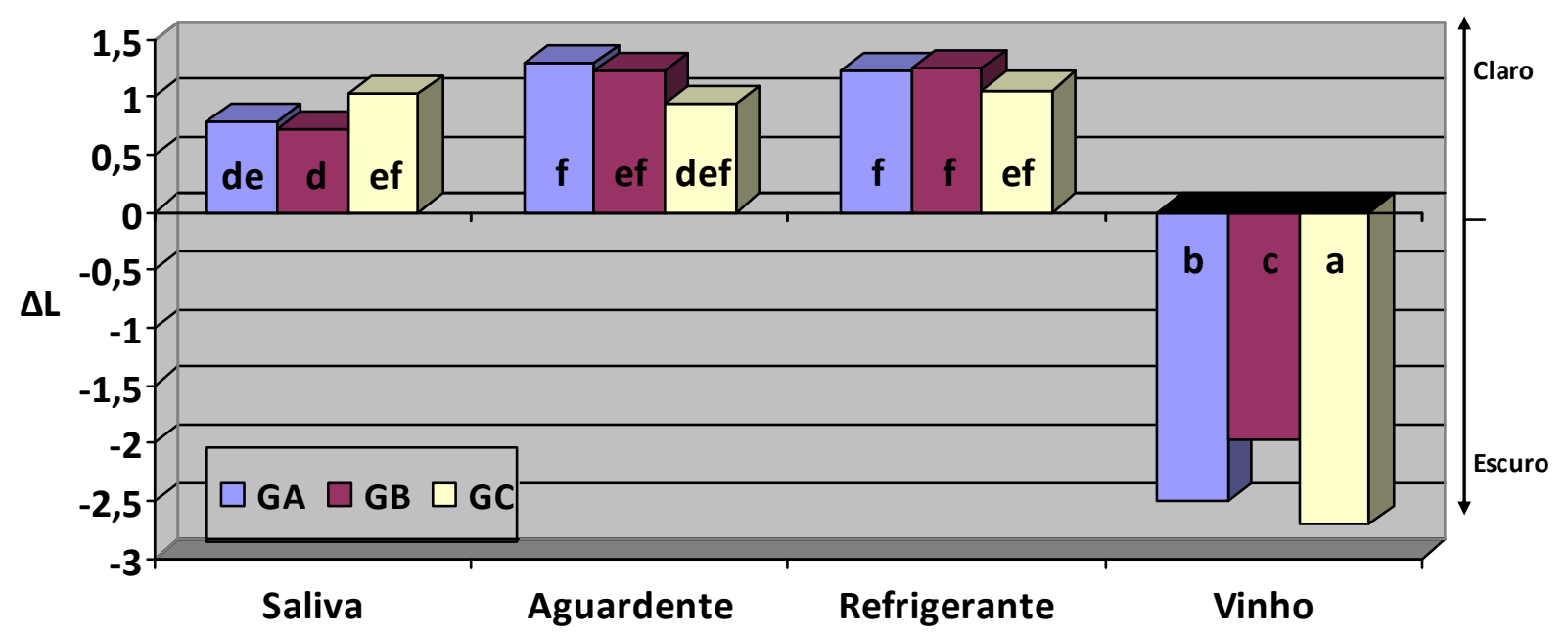

Figura 6. Valores médios de $\Delta \mathrm{L}$ na interação dos fatores escovação x soluções (Mesma letra representa similaridade estatística). 


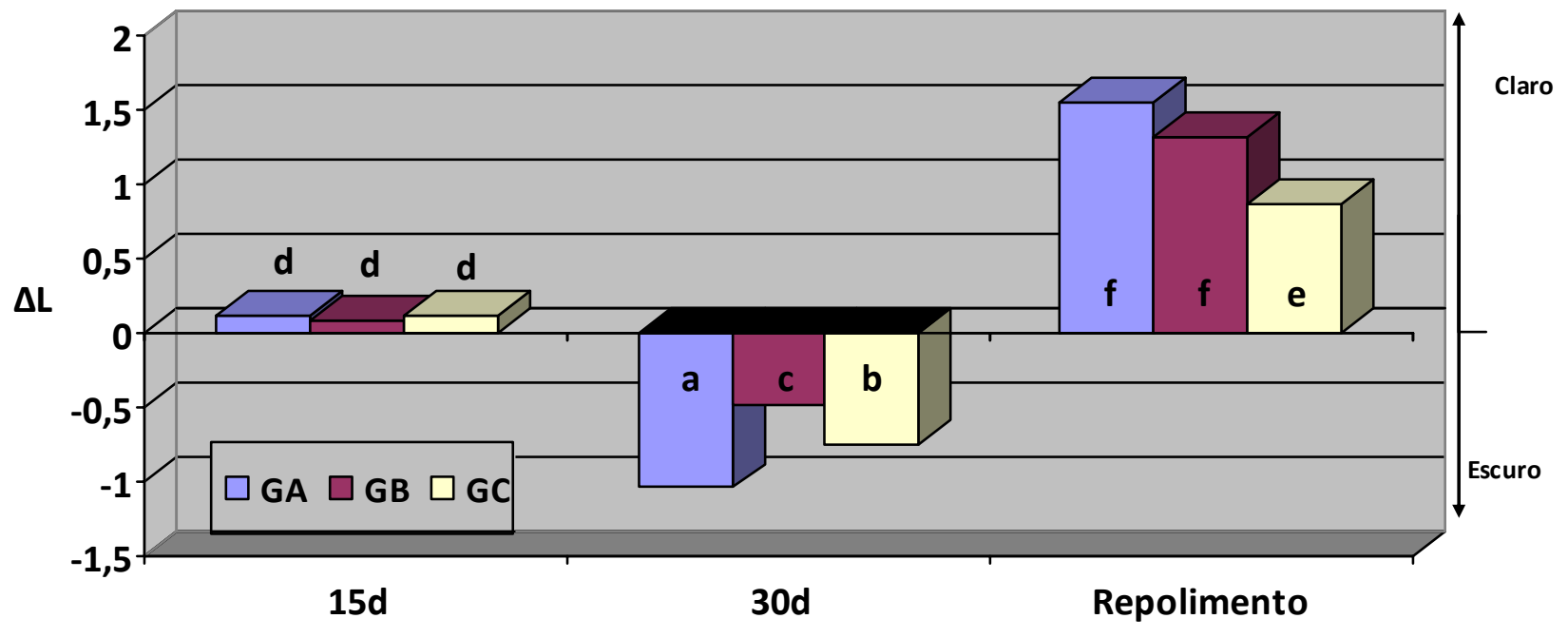

Figura 7. Valores médios de $\Delta \mathrm{L}$ na interação dos fatores escovação x tempo (Mesma letra representa similaridade estatística).

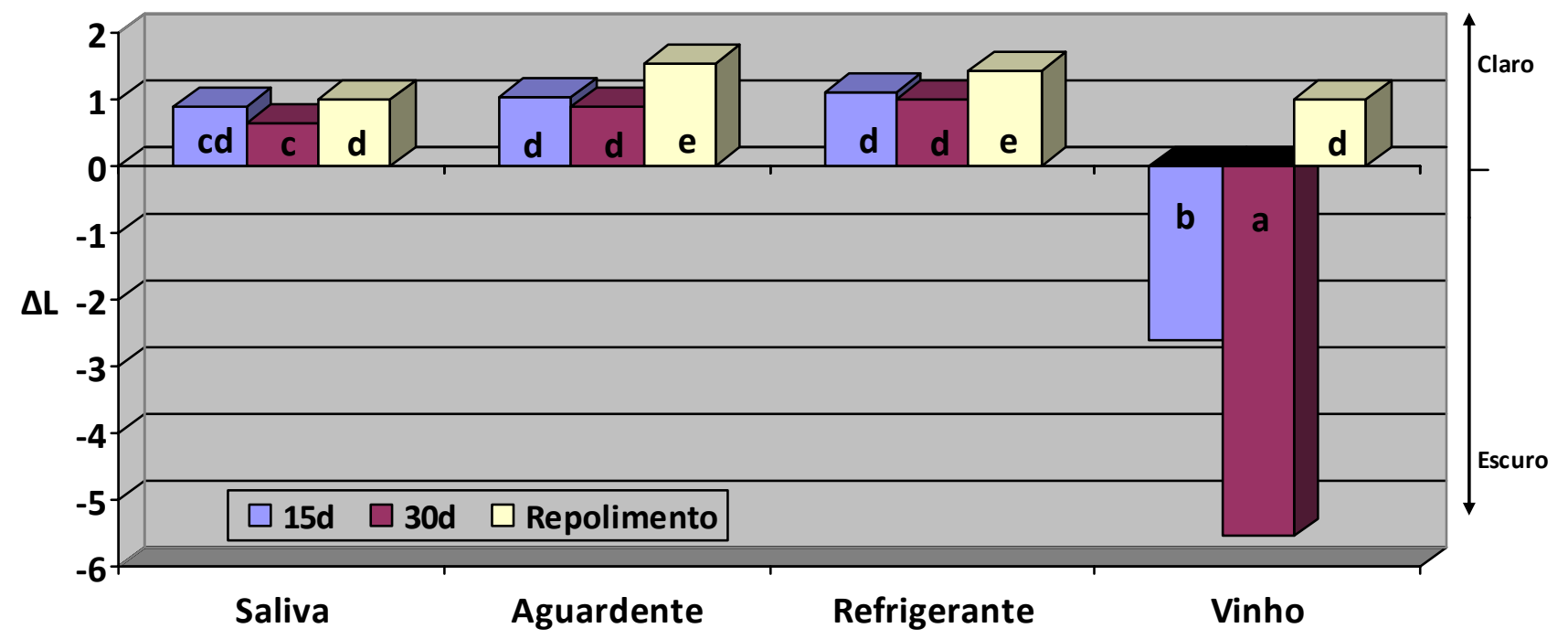

Figura 8. Valores médios de $\Delta \mathrm{L}$ na interação dos fatores tempo x soluções (Mesma letra representa similaridade estatística). 
Tabela 5. Valores de $\Delta \mathrm{L}$ médios e seus respectivos desvios-padrão dos grupos estudados.

\begin{tabular}{|c|c|c|c|c|}
\hline Grupos & Subgrupos & 15 dias & 30 dias & Repolimento \\
\hline \multirow{4}{*}{$\begin{array}{c}\text { Sem Escovação } \\
\text { (GA) }\end{array}$} & Saliva & $0,73 \pm 0,40$ & $0,45 \pm 0,41$ & $1,17 \pm 0,40$ \\
\hline & Aguardente & $1,13 \pm 0,24$ & $0,73 \pm 0,17$ & $2,05 \pm 0,60$ \\
\hline & Refrigerante & $1,08 \pm 0,47$ & $0,82 \pm 0,37$ & $1,78 \pm 0,52$ \\
\hline & Vinho Tinto & $-2,51 \pm 0,51$ & $-6,16 \pm 0,78$ & $1,18 \pm 0,47$ \\
\hline \multirow{5}{*}{$\begin{array}{l}\text { Colgate } \\
\text { (GB) }\end{array}$} & Saliva & $0,78 \pm 0,26$ & $0,64 \pm 0,34$ & $0,73 \pm 0,98$ \\
\hline & Aguardente & $0,96 \pm 0,32$ & $1,06 \pm 0,28$ & $1,65 \pm 0,34$ \\
\hline & Refrigerante & $1,13 \pm 0,76$ & $1,08 \pm 0,73$ & $1,53 \pm 0,71$ \\
\hline & Vinho Tinto & $-2,54 \pm 0,81$ & $-4,75 \pm 1,01$ & $1,33 \pm 0,95$ \\
\hline & Saliva & $1,12 \pm 0,32$ & $0,83 \pm 0,38$ & $1,10 \pm 0,50$ \\
\hline \multirow{3}{*}{$\begin{array}{l}\text { Close-up } \\
\text { (GC) }\end{array}$} & Aguardente & $1,03 \pm 0,66$ & $0,93 \pm 0,64$ & $0,88 \pm 0,89$ \\
\hline & Refrigerante & $1,09 \pm 0,53$ & $1,07 \pm 0,42$ & $1,03 \pm 0,41$ \\
\hline & Vinho Tinto & $-2,74 \pm 0,60$ & $-5,85 \pm 0,50$ & $0,46 \pm 0,66$ \\
\hline
\end{tabular}

No $\Delta \mathrm{a}$ observou-se diferença estatística significante entre os grupos, tendo o controle (sem escovação) apresentado uma tendência para o amarelo $(0,49)$ e estatisticamente significante quando comparado aos grupos escovados, que foram semelhantes entre si (grupo $\mathrm{B} \cong$ Grupo $\mathrm{C}$ ). Para as soluções, a saliva apresentou menor alteração de tonalidade com diferença estatística com as demais soluções. O refrigerante e a aguardente foram semelhantes entre si e diferentes do vinho tinto, que promoveu uma intensidade maior do amarelo. Para o tempo, observou-se um aumento significativo e intenso para o tom amarelo com o passar do tempo, tendo o repolimento apresentado menor alteração (Figuras 9 e 10; Tabela 6). 


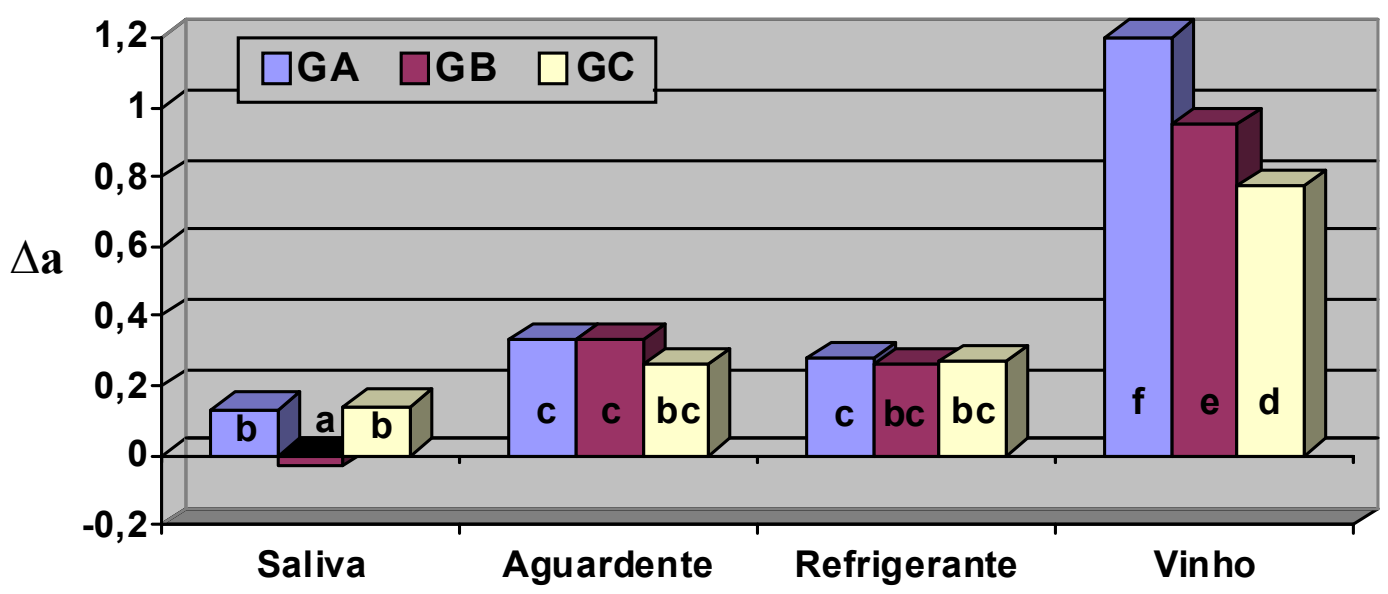

Figura 9. Valores médios de $\Delta$ a na interação dos fatores escovação x soluções (Mesma letra representa similaridade estatística).

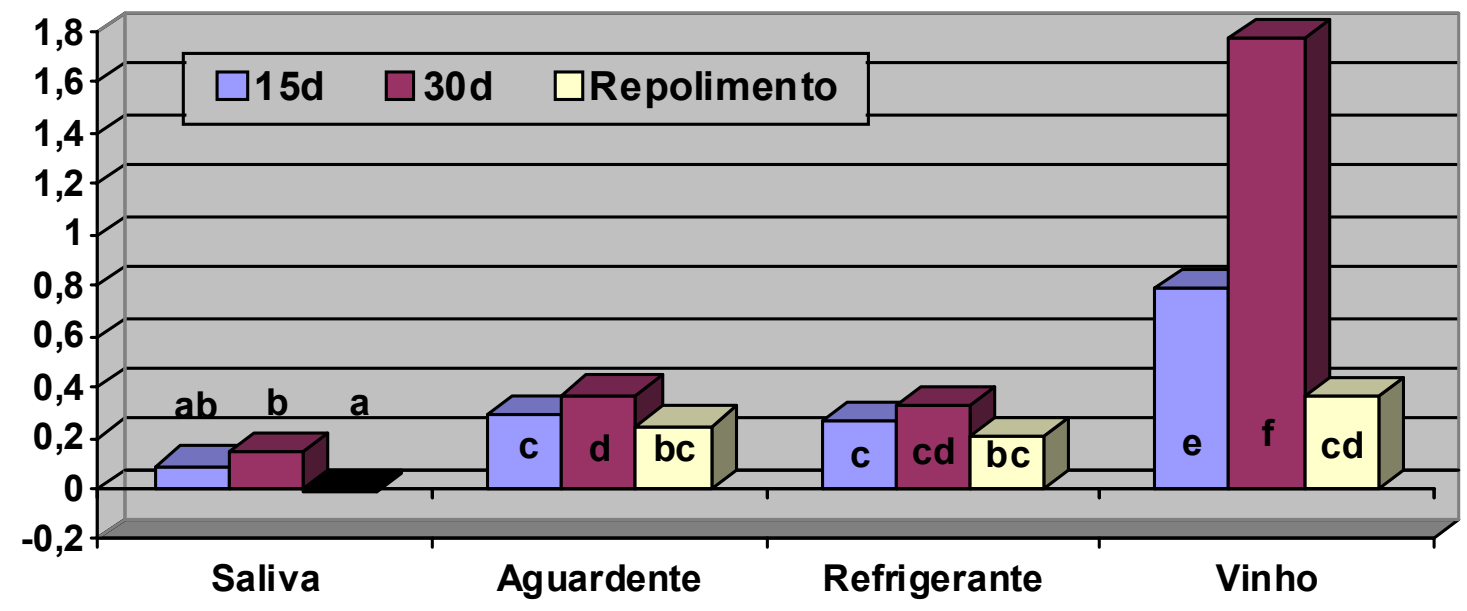

Figura 10. Valores médios de $\Delta$ a na interação dos fatores tempo x soluções (Mesma letra representa similaridade estatística). 
Tabela 6. Valores de $\Delta \mathrm{a}^{*}$ médios e seus respectivos desvios-padrão dos grupos estudados (verde, + vermelho).

\begin{tabular}{|c|c|c|c|c|}
\hline Grupos & Subgrupos & 15 dias & 30 dias & Repolimento \\
\hline & Saliva & 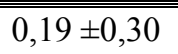 & 0,16 $\pm 0,26$ & 位 \\
\hline Sem Escovação & Aguardente & $0,35 \pm 0,09$ & $0,40 \pm 0,20$ & $0,23 \pm 0,28$ \\
\hline \multirow[t]{3}{*}{ (GA) } & Refrigerante & $0,22 \pm 0,48$ & $0,33 \pm 0,20$ & $0,30 \pm 0,22$ \\
\hline & Vinho Tinto & $0,98 \pm 0,23$ & $2,14 \pm 0,29$ & $0,49 \pm 0,18$ \\
\hline & Saliva & $0,01 \pm 0,22$ & $0,11 \pm 0,23$ & $-0,22 \pm 0,48$ \\
\hline \multirow{4}{*}{$\begin{array}{c}\text { Colgate } \\
\text { (GB) }\end{array}$} & Aguardente & $0,28 \pm 0,10$ & $0,39 \pm 0,15$ & $0,31 \pm 0,21$ \\
\hline & Refrigerante & $0,23 \pm 0,44$ & $0,35 \pm 0,35$ & $0,20 \pm 0,31$ \\
\hline & Vinho Tinto & $0,69 \pm 0,25$ & $1,69 \pm 0,29$ & $0,47 \pm 0,26$ \\
\hline & Saliva & $0,08 \pm 0,21$ & $0,19 \pm 0,20$ & $0,15 \pm 0,27$ \\
\hline \multirow{3}{*}{$\begin{array}{c}\text { Close-up } \\
\text { (GC) }\end{array}$} & Aguardente & $0,24 \pm 0,23$ & $0,33 \pm 0,38$ & $0,20 \pm 0,39$ \\
\hline & Refrigerante & $0,35 \pm 0,26$ & $0,31 \pm 0,31$ & $0,14 \pm 0,32$ \\
\hline & Vinho Tinto & $0,70 \pm 0,19$ & $1,50 \pm 0,44$ & $0,12 \pm 0,44$ \\
\hline
\end{tabular}

Para o $\Delta$ b verificou-se que o grupo sem escovação (GA) apresentou menor alteração de tonalidade, sendo estatisticamente significante em relação aos grupos escovados, que apresentaram comportamentos semelhantes com a tonalidade para o verde. A saliva foi que menos alterou este eixo, com diferença estatística para todas as soluções testadas, que por sua vez foram semelhantes entre si. Contudo, para o tempo, observou-se que o repolimento aumentou a intensidade do verde de forma superior aos 30 dias de imersão (Tabela 7). 
Tabela 7. Valores de $\Delta \mathrm{b}^{*}$ médios e seus respectivos desvios-padrão dos grupos estudados ( azul, + amarelo).

\begin{tabular}{|c|c|c|c|c|}
\hline Grupos & Subgrupos & 15 dias & 30 dias & Repolimento \\
\hline & S Saliva Artificial & 0,24 $\pm 0,39$ & 0,32 $\pm 0,24$ & 0,15 00,28 \\
\hline Sem Escovação & Aguardente & $-1,47 \pm 0,44$ & $-1,52 \pm 0,60$ & $-1,51 \pm 0,47$ \\
\hline \multirow[t]{3}{*}{ (GA) } & Refrigerante & $-1,61 \pm 0,82$ & $-1,69 \pm 0,62$ & $-1,84 \pm 0,66$ \\
\hline & Vinho Tinto & $-1,65 \pm 0,43$ & $-1,62 \pm 0,36$ & $-2,19 \pm 0,45$ \\
\hline & Saliva Artificial & $-0,36 \pm 0,55$ & $-0,11 \pm 0,53$ & $-0,60 \pm 0,78$ \\
\hline Colgate & Aguardente & $-1,86 \pm 0,58$ & $-1,86 \pm 0,75$ & $-1,79 \pm 0,71$ \\
\hline \multirow[t]{3}{*}{ (GB) } & Refrigerante & $-1,85 \pm 0,98$ & $-1,73 \pm 0,96$ & $-1,79 \pm 1,01$ \\
\hline & Vinho Tinto & $-1,82 \pm 0,60$ & $-1,27 \pm 0,39$ & $-1,30 \pm 0,65$ \\
\hline & Saliva Artificial & $-0,77 \pm 0,74$ & $-0,74 \pm 0,78$ & $-0,91 \pm 0,95$ \\
\hline Close-up & Aguardente & $-1,59 \pm 0,67$ & $-1,36 \pm 0,62$ & $-1,41 \pm 0,80$ \\
\hline \multirow[t]{2}{*}{$(\mathrm{GC})$} & Refrigerante & $-1,45 \pm 0,39$ & $-1,62 \pm 0,30$ & $-1,97 \pm 0,51$ \\
\hline & Vinho Tinto & $-1,45 \pm 0,49$ & $-1,61 \pm 0,55$ & $-2,12 \pm 0,58$ \\
\hline
\end{tabular}

\subsection{Rugosidade superficial}

Em relação à escovação, foi observado que a escovação aumentou a rugosidade superficial da resina composta, independentemente do dentifrício utilizado (Tabela 8), ou seja, os espécimes escovados apresentaram valores de rugosidade estatisticamente superiores quando comparados com o grupo sem escovação. Analisando o fator soluções, os espécimes armazenados em saliva artificial (controle) apresentaram os menores valores de rugosidade superficial.

Observando a interação escovação x soluções (Figura 11), é possível afirmar que os espécimes que não foram escovados apresentaram os menores valores de rugosidade em todas 
as soluções, quando comparados com as demais associações solução/escovação. Pode-se observar na Tabela 8 que nenhuma solução isoladamente pôde promover um aumento significativo da rugosidade, contudo, quando associado ao Dentifrício B, pode-se observar que, principalmente o refrigerante, promoveu uma alteração significativa da textura superficial.

Tabela 8. Alteração de rugosidade superficial $(\mathrm{Ra}-\mu \mathrm{m})$ média e respectivos desvios-padrão dos grupos estudados.

\begin{tabular}{ccccc}
\hline \hline Grupos & Saliva & Aguardente & Refrigerante & Vinho Tinto \\
\hline \hline GA & $-0,01 \pm 0,01 \mathrm{a}$ & $0,00 \pm 0,02 \mathrm{ab}$ & $0,02 \pm 0,02 \mathrm{~b}$ & $0,02 \pm 0,02 \mathrm{~b}$ \\
$\mathrm{~GB}$ & $0,10 \pm 0,04 \mathrm{c}$ & $0,20 \pm 0,04 \mathrm{e}$ & $0,24 \pm 0,04 \mathrm{e}$ & $0,20 \pm 0,06 \mathrm{e}$ \\
$\mathrm{GC}$ & $0,16 \pm 0,03 \mathrm{~d}$ & $0,16 \pm 0,02 \mathrm{~d}$ & $0,16 \pm 0,03 \mathrm{~d}$ & $0,15 \pm 0,04 \mathrm{~d}$ \\
\hline \hline
\end{tabular}

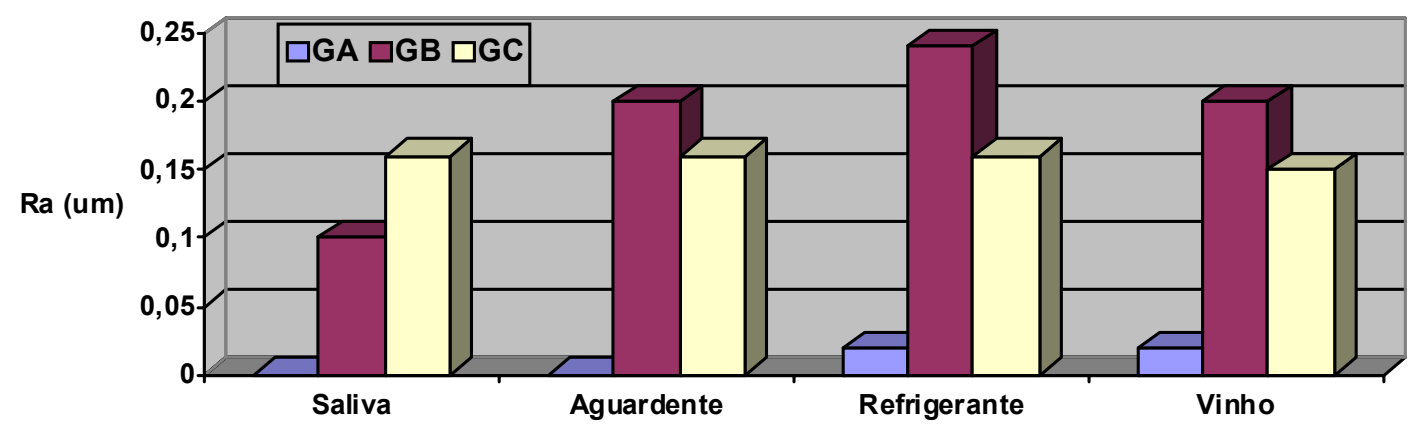

Figura 11. Valores médios de rugosidade na interação dos fatores escovação x soluções.

\subsection{Microdureza em Profundidade}

Primeiramente realizou-se uma análise prévia dos dados e como não se observou diferença significante entre as profundidades analisadas, foi realizada uma média geral para 
cada espécime. Em relação à microdureza, não houve diferença estatisticamente significativa entre os grupos estudados (Tabela 9).

Tabela 9. Valores médio da microdureza (HK) e respectivos desvios-padrão dos grupos nas diferentes profundidades analisadas.

\begin{tabular}{|c|c|c|c|c|c|}
\hline & $\begin{array}{c}\text { Profundidade } \\
(\mu \mathrm{m})\end{array}$ & $\overline{\text { Saliva }}$ & Aguardente & Refrigerante & Vinho Tinto \\
\hline \multirow{6}{*}{ GA } & 30 & $88,53 \pm 9,31$ & $91,64 \pm 7,78$ & $93,37 \pm 5,33$ & $85,16 \pm 6,16$ \\
\hline & 60 & $89,78 \pm 10,36$ & $95,44 \pm 6,79$ & $97,25 \pm 5,52$ & $91,53 \pm 9,65$ \\
\hline & 90 & $92,63 \pm 9,35$ & $99,63 \pm 9,65$ & $95,02 \pm 6,15$ & $90,98 \pm 8,77$ \\
\hline & 120 & $89,67 \pm 12,50$ & $96,10 \pm 8,75$ & $95,42 \pm 10,03$ & $91,80 \pm 7,28$ \\
\hline & 250 & $90,47 \pm 11,80$ & $98,27 \pm 7,28$ & $95,93 \pm 7,86$ & $94,80 \pm 7,53$ \\
\hline & Média & $90,22 \pm 10,10$ & $96,22 \pm 6,96$ & $95,40 \pm 5,74$ & $90,85 \pm 6,70$ \\
\hline \multirow{6}{*}{ GB } & 30 & $92,51 \pm 7,33$ & $87,75 \pm 5,84$ & $899,59 \pm 5,04$ & $89,39 \pm 4,07$ \\
\hline & 60 & $94,96 \pm 7,53$ & $90,15 \pm 6,24$ & $93,26 \pm 2,90$ & $93,79 \pm 2,68$ \\
\hline & 90 & $97,84 \pm 7,94$ & $92,18 \pm 5,03$ & $94,00 \pm 2,72$ & $93,70 \pm 4,21$ \\
\hline & 120 & $95,28 \pm 7,57$ & $94,17 \pm 2,61$ & $94,83 \pm 4,87$ & $93,65 \pm 4,55$ \\
\hline & 250 & $98,41 \pm 7,60$ & $93,80 \pm 5,24$ & $94,98 \pm 4,80$ & $94,32 \pm 5,75$ \\
\hline & Média & $95,80 \pm 6,68$ & $91,61 \pm 4,19$ & $93,33 \pm 3,08$ & $92,97 \pm 3,31$ \\
\hline \multirow{6}{*}{$\mathrm{GC}$} & 30 & $88,06 \pm 8,18$ & $90,44 \pm 5,55$ & $889,34 \pm 8,90$ & $90,38 \pm 7,79$ \\
\hline & 60 & $93,78 \pm 12,81$ & $96,45 \pm 8,01$ & $93,77 \pm 10,02$ & $92,16 \pm 5,81$ \\
\hline & 90 & $98,87 \pm 13,89$ & $98,61 \pm 11,12$ & $95,22 \pm 5,60$ & $94,27 \pm 5,02$ \\
\hline & 120 & $96,17 \pm 16,56$ & $97,83 \pm 10,48$ & $98,04 \pm 11,16$ & $94,87 \pm 6,65$ \\
\hline & 250 & $96,47 \pm 5,57$ & $101,08 \pm 10,51$ & $96,93 \pm 5,98$ & $94,93 \pm 8,20$ \\
\hline & Média & $94,67 \pm 10,30$ & $96,88 \pm 7,92$ & $94,66 \pm 7,58$ & $93,32 \pm 6,07$ \\
\hline
\end{tabular}


5.Discussão 


\section{DISCUSSÃO}

Com o aperfeiçoamento dos materiais restauradores e a demanda por restaurações estéticas, a resina composta é o material de escolha para restaurações de dentes anteriores. Porém, apesar da melhoria de suas propriedades físico-químicas, a estabilidade de cor ainda é uma limitação na longevidade das restaurações.

Há na literatura ${ }^{1,21,46,58,77,78,101,105,131}$ um grande número de estudos que relatam que os materiais resinosos são susceptíveis ao manchamento após imersão em soluções como café, chá e outras bebidas. No entanto, quando se refere à associação imersão em soluções/escovação, poucos estudos foram realizados com o objetivo de demonstrar as alterações ocorridas nas propriedades físicas dos compósitos.

A alteração de cor pode ser avaliada visualmente ou por instrumentos de medição, estes últimos proporcionam a vantagem da eliminação da subjetividade do observador. Mesmo assim, as medições de cor espectrofotométricas podem variar dependendo das condições instrumentais, isto é, a forma como a amostra é iluminada, como a intensidade da luz refletida é medida e que tipo de luz padrão é usado. No presente estudo, empregou-se espectrocolorímetro de superfície que emprega o sistema CIELab, no qual se considera os eixos L (luminosidade), a e b, compondo o $\Delta \mathrm{E}$, que matematicamente expressa a quantidade da diferença entre as coordenadas $\mathrm{L}^{*} \mathrm{a} \mathrm{b}^{*}$ do sistema de cor, e está relacionada com a percepção de cor do olho humano para 3 coordenadas. Este sistema é aproximadamente um espaço uniforme de cor com coordenadas de luminosidade, denominada $\mathrm{L}^{*}$ branco-preto, a* vermelho-verde e b* amarelo-azul. ${ }^{32,87}$

A cor e a aparência dos dentes são fenômenos complexos influenciados por muitos fatores, tais como: condição de iluminação, translucidez, opacidade, espalhamento de luz e brilho de substância. ${ }^{66}$ Dentre das propriedades ópticas, vale ressaltar a translucidez, que é a 
quantidade relativa de transmissão da luz, ou croma de refletância difusa da superfície do substrato através de um meio turvo. Translucidez e cor de uma resina composta são caracterizadas por dois parâmetros comprimento de onda-dependentes: o coeficiente de absorção e o coeficiente de dispersão. ${ }^{18,45} \mathrm{O}$ parâmetro de translucidez é a diferença de cor de uma espessura uniforme de um material sobre um fundo preto e branco e corresponde diretamente às avaliações visuais comuns de translucidez. ${ }^{65}$ Vários estudos ${ }^{74,85,92}$ têm relatado que o fundo da cavidade bucal influencia a cor das resinas compostas e sugerem que as características de transmitância luminosa podem desempenhar um papel importante para a cor das resinas compostas. Quando um fundo sólido é utilizado, as alterações nos parâmetros de cor causadas pelos efeitos de filtragem de um material translúcido ao longo de um fundo resultam da interação do espalhamento óptico e da absorção, da espessura do material e da reflectância do fundo. ${ }^{88}$ Por este motivo, deve-se padronizar o tipo de fundo, para que se possa realmente analisar a quantidade de variação da cor apresentada após o envelhecimento. Dentro deste contexto, o presente estudo empregou um fundo branco e um posicionador sobre o fundo para que sempre as leituras fossem realizadas com o espécime posicionado sobre o mesmo local do fundo e na mesma posição da leitura inicial.

Entretanto, foi observado que algumas pesquisas ${ }^{10,74}$ sobre medição de cor dental não identificaram o tipo de fundo usado, e outros empregaram vários fundos, incluindo branco, preto, colorido ou da cor dos dentes, ou luz na superfície dental. Independentemente do tipo de fundo, o valor da diferença de cor $\Delta \mathrm{E}^{*}$ será consistente quando a cor for medida com o mesmo fundo. Por outro lado, valores de $\Delta \mathrm{E}^{*}$ em diferentes fundos não podem ser comparados. $^{74}$

No presente estudo pode-se observar que as soluções afetaram a cor dos espécimes, principalmente o vinho tinto, que levou a uma alteração acentuada da cor. Resultados 
similares foram encontrados na literatura ${ }^{35}$ em que este tipo de bebida foi empregado, pois o vinho tinto apresenta alta concentração de pigmentos ${ }^{35}$, visivelmente maior do que outras bebidas. Além dos valores mais altos atingidos pelo vinho, a intensidade da alteração de cor alcançada seria clinicamente perceptível. A literatura ${ }^{64}$ relata que restaurações são consideradas aceitáveis em relação à sua cor com valor de $\Delta \mathrm{E}^{*}$ ab inferior ao valor de 3,7 . Porem 50\% dos observadores consideraram uma restauração inaceitável quando o valor de $\Delta \mathrm{E}^{*}$ ab foi aproximadamente $3,3 .{ }^{101}$ Estudo sobre a correlação de valores de $\Delta \mathrm{E}^{*}$ ab e respostas de observação humana verificaram que existe uma relação específica entre a magnitude e direção das medições e as respostas médias observadas. ${ }^{108}$ Entretanto, independente do nível de aceitabilidade do $\Delta \mathrm{E}^{*}$, no presente estudo, o vinho alcançou níveis superiores quanto aos limiares de diferenças de cor perceptível/aceitável, sendo que os limiares de aceitabilidade variam para as tonalidades, e são $\Delta \mathrm{E}^{*}=1,1$ para tons de vermelho e 2,1 para tons de amarelo. ${ }^{31}$

Os manchamentos ocasionados pela aguardente $(\Delta \mathrm{E}=2,09 ; \Delta \mathrm{E} 30 \mathrm{~d}=1,93)$ e refrigerante $(\Delta \mathrm{E}=2,23 ; \Delta \mathrm{E} 30 \mathrm{~d}=2,08)$ foram inferiores ao vinho tinto $(\Delta \mathrm{E}=3,88 ; \Delta \mathrm{E} 30 \mathrm{~d}=6,08)$, entretanto mais intenso que o controle (saliva artificial $-\Delta \mathrm{E}=1,18 ; \Delta \mathrm{E} 30 \mathrm{~d}=0,93$ ). Este fato provavelmente pode ser explicado pelas características das soluções, que podem promover a degradação química da matriz orgânica em maior ou menor intensidade e conseqüentemente favorecer o manchamento do material. A presença de álcool nas soluções estudadas pode ter proporcionado o amolecimento da resina ${ }^{6}$ e, conseqüentemente, promovido uma degradação irreversível do material. Nesta pesquisa, a saliva artificial promoveu uma ligeira alteração de cor nos espécimes $(\Delta \mathrm{E}=1,18)$, levemente perceptível, ${ }^{21}$ semelhante aos observados por Omata e colaboradores $^{89}$ (2006). Segundo os autores, a saliva artificial pode promover manchamento pela presença de mucina em sua composição, que é uma substancia de cor amarelada. Contudo, neste estudo, essa justificativa não se enquadra por dois motivos: a saliva artificial utilizada não apresentava mucina em sua composição e a variação de cromaticidade do eixo 
azul-amarelo apresentou-se negativa $(\Delta \mathrm{b}=-0,31)$, demonstrando uma tendência da cor para $\mathrm{o}$ azul e não para o amarelo. Portanto, duas hipóteses podem ser levantadas: a primeira seria a deposição de minerais sobre a superfície dos espécimes formando uma película esbranquiçada; a segunda seria o aumento da luminosidade $\left(\Delta \mathrm{L}_{30 \mathrm{~d}}=0,64\right)$ dos espécimes imersos em saliva artificial.

A escovação, de um modo geral, não foi capaz de minimizar a alteração de cor da resina, sugerindo que ocorre manchamento intrínseco além do extrínseco, ou seja, o manchamento intrínseco é modulado pela taxa de conversão e características físico-químicas da resina composta - sendo de especial importância a taxa de absorção de água. ${ }^{29,120}$ Outros fatores importantes que afetam a estabilidade de cor são a rugosidade superficial, integridade superficial e técnicas de polimento.

A descoloração de resinas compostas pode ser induzida interna ou externamente. Além da canforoquinona, outros componentes do sistema foto-iniciador, denominados aromáticos terciários ou aminas alifáticas, que agem como os chamados sinergistas ou aceleradores, também tendem a causar descoloração amarela ou marrom sob a influência da luz ou calor. ${ }^{62}$ Estas são descolorações induzidas internamente, que são permanentes e estão relacionadas com a qualidade dos polímeros, tipo e quantidade das partículas de carga, bem como com o agente adicionado ao sistema foto-iniciador. ${ }^{56,76,107}$ Como os profissionais não podem interferir no conteúdo das resinas compostas, a descoloração interna do material pode ser devido à fotopolimerização inadequada.

Uma diminuição na potência da luz e/ou uma alteração no comprimento de onda irá causar um baixo grau de conversão do monômero, o que afetará a estabilidade da cor do compósito. ${ }^{59} \mathrm{O}$ grau de polimerização depende do percentual da conversão ou da relação de duplas ligações convertidas. Compósitos com uma percentagem de conversão mais elevada 
têm melhores propriedades mecânicas, maior resistência ao desgaste e melhor estabilidade de cor. ${ }^{38}$ Também é conhecido que as uretanas não apresentam polimerização completa em sua cadeia polimérica, e isto pode justificar a penetração de pigmentos em áreas deficientes. A afinidade da matriz orgânica da resina por corantes é modulada pelo grau de conversão dos monômeros; ${ }^{30}$ portanto, uma conversão insuficiente pode aumentar a absorção de corantes. A cor intrínseca do material também pode se alterar com o envelhecimento do mesmo sob várias condições físico-químicas: exposição à luz visível ou à irradiação ultravioleta, mudanças térmicas e umidade ${ }^{19,40}$ ou mesmo pelo tipo de material empregado. ${ }^{35}$ No presente estudo foi testada apenas uma marca comercial de resina composta e empregou-se sempre o mesmo equipamento de fotoativação, que foi monitorado durante toda a fase experimental para padronizar e conseguir avaliar corretamente as propriedades analisadas.

Além do mais, a descoloração do material pode ser afetada pelas condições do meio bucal e pelo tempo exposto na cavidade bucal, ${ }^{19,56,79,93,130}$ como foi observado no presente estudo, em que se verificou que quanto maior o tempo de ciclagem mais intensa foi a modificação da cor. Esses dados são discordantes de outros trabalhos encontrados na literatura, ${ }^{93,130}$ que observaram que as resinas compostas avaliadas sofreram maior manchamento entre as primeiras 24 horas e 7 dias.

A discordância existente entre os valores desta pesquisa com relação ao fator tempo e aquele encontrado na literatura ${ }^{130}$ pode ser atribuída à diferença entre as metodologias, pois, naquele, os corpos-de-prova eram imersos em seus respectivos meios de imersão durante todo o período do experimento e, neste estudo, procurou-se simular uma situação clínica ${ }^{98,103}$ e, desta forma, os espécimes foram imersos em seus meios de imersão por apenas 25 minutos diários. 
Observou-se também neste trabalho que não houve diferença na estabilidade de cor entre espécimes escovados (GB e GC) e não escovados (GA), independentemente do dentifrício utilizado, demonstrando que apesar da maior rugosidade dos espécimes escovados, isto não se refletiu na alteração de cor. Este fato pode ser justificado, pois, embora superfícies ásperas sejam descoloridas pela adsorção de pigmentos, alguns estudos ${ }^{95,111}$ demonstraram não existir correlação entre rugosidade superficial e manchamento.

Na verdade, a rugosidade superficial está relacionada a uma combinação de fatores, como o tamanho, a dureza e o percentual de área superficial ocupada pelas partículas de preenchimento, ${ }^{33,61}$ a composição do monômero, ${ }^{116}$ o grau de conversão da matriz polimérica da matriz resinosa, ${ }^{68}$ e a interação matriz/partícula, bem como a estabilidade da união do silano. $^{68}$

Apesar de este estudo ter empregado um único tipo de resina composta (marca comercial), as propriedades do material também variam de acordo com o meio de imersão, 5,13 justificando as alterações ocorridas nas propriedades analisadas, uma vez que os espécimes foram imersos em diferentes soluções.

A textura superficial controla o grau de dispersão ou de reflexão de luz incidente sobre os dentes e restaurações dentárias. Em geral, resinas compostas polidas tendem a aparecer mais claras, brancas e menos brilhantes do que as superfícies correspondentes cobertas com uma tira de polietileno. ${ }^{113}$ Embora uma superfície de alto brilho seja geralmente considerada menos suscetível ao manchamento, ${ }^{30,110,122}$ outras condições da superfície, tal como incompleta polimerização da matriz da resina, podem contribuir para o manchamento das resinas compostas. $^{37}$

Uma tira de poliéster produz a superfície mais lisa em comparação com aquelas após procedimentos de acabamento e polimento para as resinas compostas híbridas e de nano- 
partículas. ${ }^{15}$ No entanto, em outro estudo, ${ }^{94}$ foi relatado que as superfícies mais lisas em resinas compostas não eram necessariamente as mais resistentes ao manchamento. Desta forma, optou-se neste estudo pela realização de polimento ao invés da utilização de tira de poliéster.

As restaurações de resina composta são desgastadas predominantemente pela escovação com dentifrício. ${ }^{9}$ Este desgaste é influenciado por vários fatores, como o tipo da escova dental, o dentifrício, a máquina de abrasão-escovação, o número de movimentos, condição tampão e a carga aplicada à escovação. ${ }^{116}$

Como resultado da abrasão pela escovação, bem como pelo processo corrosivo (erosivo), os materiais restauradores podem tornar-se rugosos $^{44,81,100,116}$ e sofrer desgaste. ${ }^{12,20,81,116}$ A presença de irregularidades pode influenciar a aparência, levar a uma descoloração superficial, retenção de biofilme bacteriano e irritação gengival, ${ }^{22,110}$ aumentando o risco de cárie e inflamação periodontal. Sugere-se que a rugosidade é resultado da perda de matriz das partículas de preencimento. ${ }^{99}$

Em relação à microdureza, estudos prévios $^{52,134}$ têm demonstrado resultados conflitantes na correlação entre dureza do material e resistência ao desgaste. Além do mais, este processo é complexo, dependendo das condições encontradas na cavidade bucal, incluindo os movimentos mandibulares e contatos prematuros, ${ }^{23}$ bem como a ação da escovação ${ }^{34,67}$ e dos componentes químicos, térmicos e biológicos que podem afetar o corpo do material e, dessa forma, levar ao desgaste superficial. ${ }^{119}$ A quantidade de desgaste sofrida pela resina composta está diretamente relacionada à sua composição, desde o tipo e tamanho da carga ${ }^{106}$ até a adição de partículas à matriz e grau de adesão desta à porção orgânica. ${ }^{124}$ 
No presente estudo, apesar de não ter sido analisada a correlação entre rugosidade superficial e microdureza, foi observado que não houve diferença na microdureza dos espécimes, sugerindo que a escovação e as soluções não tenham diminuído a microdureza.

Embora as soluções afetarem negativamente a estabilidade de cor, a escovação não aumentou a intensidade do manchamento e nem diminuiu a microdureza dos espécimes. Desta forma, novos estudos são necessários para estabelecer se há correlação entre estabilidade de cor, rugosidade superficial, desgaste e microdureza, assim como para avaliar se há influência do tempo nestas propriedades das resinas compostas. 


\section{CONCLUSÕES}

Baseado na metodologia empregada, nos resultados obtidos e nas restrições de um estudo in vitro, pode-se concluir que:

- A estabilidade de cor foi influenciada apenas pelas bebidas: o vinho tinto apresentou as maiores alterações;

- O repolimento não promoveu o retorno à cor inicial dos espécimes;

- As bebidas e a escovação influenciaram negativamente na rugosidade da superfície: o dentifrício Colgate proporcionou um aumentou mais intenso da rugosidade;

- Em relação à microdureza, não houve diferença entre os grupos estudados. 
7.Referências Bibliográficas 


\section{REFERÊNCIAS BIBLIOGRÁFICAS*}

1. Abu-Bakr N, Han L, Okamoto A, Iwaku M. Color stability of compomer after immersion in various media. J Esthet Dent. 2000; 12(5):258-63.

2. Albers HF. Tooth-colored Restoratives. Principles and Techniques $9^{\text {th }}$ ed BC Decker Inc London. 2002.

3. Al-Negrish AR. Composite resin restorations: a cross-sectional survey of placement and replacement in Jordan. Int Dent J. 2002; 52(6):461-8.

4. Alvim HH, Alecio AC, Vasconcellos WA, Furlan M, de Oliveira JE, Saad JR. Analysis of camphorquinone in composite resins as a function of shade. Dent Mater. 2007; 23(10):12459.

5. Asmussen E, Hansen EK. Surface discoloration of restorative resins in relation to surface softening and oral hygiene. Scand J Dent Res. 1986; 94(2):174-7.

6. Asmussen E, Peutzfeldt A. Two-step curing: influence on conversion and softening of a dental polymer. Dent Mater. 2003; 19(6):466-70.

7. Asmussen E. Factors affecting the color stability of restorative resins. Acta Odontol Scand. 1983; 41(1):11-8.

8. Asmussen E. Factors affecting the quantity of remaining double bonds in restorative resin polymers. Scand J Dent Res. 1982; 90(6):490-6.

9. Asmussen E. Clinical relevance of physical, chemical and bonding properties of composite resins. Oper Dent. 1985; 10(2):61-73.

10. ASTM E. Standard Practice for Identification of Instrumental Methods of Color or ColorDifference Measurement of Materials. West Conshohocken (PA): ASTM; 1981. (reaproved in 1987).

\footnotetext{
${ }^{*}$ De acordo com o estilo Vancouver. Disponível em http://www.nlm.nih.gov/bsd/uniform_requiriments.html. Abreviaturas dos periódicos em conformidade com Baseline.
} 
11. Atkinson JC, Diamond F, Eichmiller F, Selwitz R, Jones G. Stability of bisphenol A, triethylene-glycol dimethacrylate, and bisphenol A dimethacrylate in whole saliva. Dent Mater. 2002; 18(2):128-35.

12. Attin T. Toothbrushing abrasion of polyacid-modified composites in neutral and acidic buffer solutions. J Prosthet Dent. 1998; 80(2):148-50.

13. Bagheri R, Burrow MF, Tyas M. Influence of food-simulating solutions and surface finish on susceptibility to staining of aesthetic restorative materials. J Dent. 2005; 33(5):389-98

14. Bailey SJ, Swift EJ Jr. Effect of home bleaching products on composite resins. Quintessence Int. 1992; 23(7):489-94.

15. Baseren M. Surface roughness of nanofill and nanohybrid composite resin and ormocerbased tooth-colored restorative materials after several finishing and polishing procedures. $\mathbf{J}$ Biomater Appl. 2004; 19(2):121-34.

16. Borges AB, Marsilio AL, Pagani C, Rodrigues JR. Surface roughness of packable composite resins polished with various systems. J Esthet Restor Dent. 2004; 16(1):42-7.

17. Brada VV, Faraoni JJ, Ramos RP, Palma-Dibb RG. Influence of different beverages on the microhardness and surface roughness of resin composites. Oper Dent. 2005; 30(2):213219.

18. Broadbelt RH, O’Brien WJ, Fan PL. Translucency of dental porcelains. J Dent Res. 1980; 59(1):70-5.

19. Buchalla W, Attin T, Hilgers RD, Hellwig E. The effect of water and light exposure on the color and translucency of a hybrid and a microfilled composite. J Prosthet Dent. 2002; 87(7):264-70.

20. Buchalla W, Attin T, Hellwig E. Brushing abrasion of luting cements under neutral and acidic conditions. Oper Dent. 2000; 25(6):482-7.

21. Burrow MF, Makinson OF. Color change in light-cured resins exposed to daylight. Quintessence Int. 1991; 22(6):447-52. 
22. Chan KC, Fuller JL, Hormati AA. The ability of foods to stain two composite resins. J Prosthet Dent. 1980; 43(5):542-5.

23. Chimello DT, Palma Dibb RG, Corona SAM, Lara, EHG. Assessing wear and surface roughness of different composite resins after toothbrushing. Mater Res. 2001; 4(4):285-9.

24. Chung KH. Effects of finishing and polishing procedures on the surface texture of resin composites. Dent Mater. 1994; 10(5):325-30.

25. CIE (Commission Internationale de l'Eclairage). Colorimetry-Technical Report. CIE Pub. No. $15,2^{\text {nd }}$ ed. Vienna, Austria: Bureau Central de la CIE, 1986 (corrected reprint 1996).

26. Cooley RL, Burger KM. Effect of carbamide peroxide on composite resins. Quintessence Int. 1991; 22:817-21.

27. Craig RG. Chemistry, composition, and properties of composite resins. Dent Clin N Am. 1981; 25(2):219-39.

28. Cullen DR, Nelson JA, Sandrik JL. Peroxide bleaches: effect on tensile strength of composite resins. J Prosthet Dent. 1993; 69(3):247-9.

29. de Gee AJ, ten Harkel-Hagenaar E, Davidson CL. Color dye for identification of incompletely cured composite resins. J Prosthet Dent. 1984; 52(5):626-31.

30. Dietschi D, Campanile G, Holz J, Meyer JM. Comparison of the color stability of ten new-generation composites: an in vitro study. Dent Mater. 1994; 10(6):353-62.

31. Douglas RD, Brewer JD. Acceptability of shade differences in metal ceramic crowns. J Prosthet Dent. 1998; 79(3):254-60.

32. Douglas RD, Brewer JD. Variability of porcelain color reproduction by commercial laboratories. J Prosthet Dent. 2003; 90(4):339-46.

33. Draughn RA, Harrison A. Relationship between abrasive wear and microstructure of composite resins. J Prosthet Dent. 1978; 40(2):220-4. 
34. Ehrnford L. Surface microstructure of composite resins after toothbrush-dentifrice abrasion. Acta Odontol Scand. 1983; 41(4):241-5.

35. Ertaş E, Güler AU, Yücel AC, Köprülü H, Güler E. Color stability of resin composites after immersion in different drinks. Dent Mater J. 2006; 25(2):371-6.

36. Ferracane JL, Berge HX, Condon JR. In vitro aging of dental composites in water: effect of degree of conversion, filler volume, and filler/matrix coupling. J Biomed Mater Res. 1998; 42(3):465-72.

37. Ferracane JL, Condon JR, Mitchem JC. Evaluation of subsurface defects created during the finishing of composites. J Dent Res. 1992; 71(9):1628-32.

38. Ferracane JL, Greener EH. The effect of resin formulation on the degree of conversion and mechanical properties of dental restorative resins. J Biomed Mater Res. 1986; 20(1):12131 .

39. Ferracane JL, Marker VA. Solvent degradation and reduced fracture toughness in aged composites. J Dent Res. 1992; 71(1):13-9.

40. Ferracane JL, Moser JB, Greener EH. Ultraviolet light induced yellowing of dental restorative resins. J Prosthet Dent. 1985; 54(4):483-7.

41. Finer Y, Jaffer F, Santerre JP. Mutual influence of cholesterol esterase and pseudocholinesterase on the biodegradation of dental composites. Biomaterials. 2004; 25(10):1787-93.

42. Freund M, Munksgaard EC. Enzymatic degradation of BISGMA/TEGDMA-polymers causing decreased microhardness and greater wear in vitro. Scand J Dent Res. 1990; 98(4):351-5.

43. Friend GW, Jones JE, Wamble SH, Covington JS. Carbamide tooth bleaching: changes to composite resins after prolonged exposure. J Dent Res. 1991; 70:570.(Abstr)

44. Gladys S, Van Meerbeek B, Braem M, Lambrechts P, Vanherle G. Comparative physicomechanical characterization of new hybrid restorative materials with conventional glassionomer and resin composite restorative materials. J Dent Res. 1997; 76(4):883-94. 
45. Grajower R, Wozniak WT, Lindsay JM. Optical properties of composite resins. J Oral Rehabil. 1982; 9(5):389-99.

46. Gross MD, Moser JB. A colorimetric study of coffee and tea staining of four composite resins. J Oral Rehabil. 1977; 4(4):311-22.

47. Guler AU, Yilmaz F, Kulunk T, Guler E, Kurt S. Effects of different drinks on stainability of resin composite provisional restorative materials. J Prosthet Dent. 2005; 94(2):118-24.

48. Hachiya Y, Iwaku M, Hosoda H, Fusayama T. Relation of finish to discoloration of composite resins. J Prosthet Dent. 1984; 52(6):811-4.

49. Han L, Okamoto A, Fukushima M, Okiji T. Evaluation of flowable resin composite surfaces eroded by acidic and alcoholic drinks. Dent Mater J. 2008; 27(3):455-65.

50. Hannig C, Hannig M, Attin T. Enzymes in the acquired enamel pellicle. Eur J Oral Sci. 2005; 113(1):2-13.

51. Harrington E, Wilson HJ, Shortall AC. Light-activated restorative materials: a method of determining effective radiation times. J Oral Rehabil. 1996; 23(3):210-8.

52. Harrison A, Draughn RA. Abrasive wear, tensile strength, and hardness of dental composite resins--is there a relationship? J Prosthet Dent. 1976; 36(4):395-8.

53. Heath JR, Wilson HJ. Forces and rates observed during in vivo toothbrushing. Biom Eng. 1974; 9(2):61-4.

54. Hickel R, Heidemann D, Staehle HJ, Minnig P, Wilson NH; German Scientific Association for Operative Dentistry; European Federation of Conservative Dentistry. Direct composite restorations: extended use in anterior and posterior situations. Clin Oral Investig. 2004; 8(2):43-4.

55. Hörsted-Bindslev P, Mjör IA. Esthetic restorations. In: Modern concepts in operative dentistry. Copenhagen: Munksgaard. 1988; 190-246.

56. Hosoya Y. Five-year color changes of light-cured resin composites: influence of lightcuring times. Dent Mater. 1999; 15(4):268-74. 
57. Hunsaker KJ, Christensen GJ, Christensen RP. Tooth bleaching chemicals - influence on teeth and restorations. J Dent Res. 1990; 69:303.(Abstr)

58. Iazzetti G, Burgess JO, Gardiner D, Ripps A. Color stability of fluoride-containing restorative materials. Oper Dent. 2000; 25(6):520-5.

59. Imazato S, Tarumi H, Kobayashi K, Hiraguri H, Oda K, Tsuchitani Y. Relationship between the degree of conversion and internal discoloration of light-activated composite. Dent Mater J. 1995; 14(1):23-30.

60. Inokoshi S, Burrow MF, Kataumi M, Yamada T, Takatsu T. Opacity and color changes of tooth-colored restorative materials. Oper Dent. 1996; 21(2):73-80.

61. Jaarda MJ, Wang R, Lang BR. A regression analysis of filler particle content to predict composite wear. J Prosthet Dent. 1997; 77(1):57-67.

62. Janda R, Roulet JF, Kaminsky M, Steffin G, Latta M. Color stability of resin matrix restorative materials as a function of the method of light activation. Eur J Oral Sci. 2004; 112(3):280-5.

63. Janda R, Roulet JF, Latta M, Steffin G, Rüttermann S. Color stability of resin-based filling materials after aging when cured with plasma or halogen light. Eur J Oral Sci. 2005; 113(3):251-7.

64. Johnston WM, Kao EC. Assessment of appearance match by visual observation and clinical colorimetry. J Dent Res. 1989; 68(5):819-22.

65. Johnston WM, Ma T, Kienle BH. Translucency parameter of colorants for maxillofacial prostheses. Int J Prosthodont. 1995; 8(1):79-86.

66. Joiner A. Tooth color: a review of the literature. J Dent. 2004; 32(1):3-12.

67. Kanter J, Koski RE, Martin D. The relationship of weight loss to surface roughness of composite resins from simulated toothbrushing. J Prosthet Dent. 1982; 47(5):505-13.

68. Kaway K, Iwami Y, Ebisu S. Effect of resin monomer composition on toothbrush wear resistance. J Oral Rehabil. 1998; 25(4):264-8. 
69. Keng SB, Lim M. Denture plaque distribution and the effectiveness of a perboratecontaining denture cleanser. Quintessence Int. 1996; 27(5):341-5.

70. Kim HS, Um CM. Color differences between resin composites and shade guides. Quintessence Int. 1996; 27(8):559-67.

71. Kim JH, Lee YK, Powers JM. Influence of a series of organic and chemical substances on the translucency of resin composites. J Biomed Mater Res B Appl Biomater. 2006; 77(1):217.

72. Koishi Y, Tanoue N, Matsumura H, Atsuda M. Colour reproducibility of a photoactivated prosthetic composite with different thicknesses. J Oral Rehabil. 2001; 28(9):799804.

73. Kuehni RG, Marcus RT. An experiment in visual scaling of small color differences. Color Res Appl. 1979; 4:83-91.

74. Lee YK, Lim BS, Kim CW. Difference in the colour and colour change of dental resin composites by the background. J Oral Rehabil. 2005; 32(3):227-33.

75. Lee YK, Lim BS, Kim CW. Effect of surface conditions on the color of dental resin composites. J Biomed Mater Res. 2002; 63(5):657-63.

76. Lee YK, Lim BS, Rhee SH, Yang HC, Powers JM. Color and translucency of A2 shade resin composites after curing, polishing and thermocycling. Oper Dent. 2005; 30(4):436-42.

77. Lee YK, Lu H, Powers JM. Effect of surface sealant and staining on the fluorescence of resin composites. J Prosthet Dent. 2005; 93(3):260-6.

78. Lu H, Roeder LB, Lei L, Powers JM. Effect of surface roughness on stain resistance of dental resin composites. J Esthet Restor Dent. 2005; 17(2):102-8.

79. Minelli CJ, Chaves PHF, Silva EMC. Alteração da cor de resinas compostas. Parte I. Influência das soluções de café, chá e vinho. Rev Odontol Univ São Paulo. 1988; 2:143-7. 
80. Mjör IA, Moorhead JE, Dahl JE. Reasons for replacement of restorations in permanent teeth in general dental practice. Int Dent J. 2000; 50(6):361-6.

81. Momoi Y, Hirosaki K, Kohno A, McCabe J.F. In vitro toothbrush-dentifrice abrasion of resin-modified glass ionomers. Dent Mater. 1997; 13(2):82-8.

82. Monaghan P, Lim E, Lautenschlager E. Effects of home bleaching preparations on composite resin color. J Prosthet Dent. 1992; 68(4):575-8.

83. Monaghan P, Trowbridge T, Lautenschlager E. Composite resin color change after vital tooth bleaching. J Prosthet Dent. 1992; 67(6):778-81.

84. Montes-G GM, Draughn RA. In vitro surface degradation of composites by water and thermal cycling. Dent Mater. 1986; 2(5):193-7.

85. Nakamura T, Saito O, Mizuno M, Kinuta S, Ishigaji S. Influence of abutment substrates on the color of metal-free polymer crowns. J Oral Rehabil. 2003; 30(2):184-8.

86. Noie F, O'Keefe KL, Powers JM. Color stability of resin cements after accelerated aging. Int J Prosthodont. 1995; 8(1):51-5.

87. O'Brien WJ, Boenke KM, Groh CL. Coverage errors of two shade guides. Int J Prosthodont 1991; 4(1):45-50.

88. O’Brien WJ, Johnston WM, Fanian F. Double-layer color effects in porcelain systems. J Dent Res. 1985; 64(6):940-3.

89. Omata Y, Uno S, Nakaoki Y, Tanaka T, Sano H, Yoshida S, Sidhu SK. Staining of hybrid composites with coffee, oolong tea, or red wine. Dent Mater J. 2006; 25(1):125-31.

90. Oysaed H, Ruyter IE. Water sorption and filler characteristics of composites for use in posterior teeth. J Dent Res. 1986; 65(11):1315-8.

91. Powers JM, Dennison JB, Koran A. Color stability of restorative resins under accelerated aging. J Dent Res. 1978; 57(11-12):964-70. 
92. Powers JM, Dennison JB, Lepeak PJ. Parameters that affect the color of direct restorative resins. J Dent Res. 1978; 57(9-10):876-80.

93. Reis A, Loguercio AD, Schroeder M, Bauer JRO, Rodrigues Filho LE, Busato ALS. Avaliação da estabilidade de cor inicial de diferentes resinas compostas. Rev Bras Odontol. 2001; 58:348-50.

94. Reis AF, de Carvalho Cardoso P, Vieira LC, Baratieri LN, Grande RH, Loguercio AD. Effect of prolonged application times on the durability of resin-dentin bonds. Dent Mater. 2008; 24(5):639-44.

95. Reis AF, Giannini M, Lovadino JR, Ambrosano GM. Effects of various finishing systems on the surface roughness and staining susceptibility of packable composite resins. Dent Mater. 2003, 19(1):12-8.

96. Reis AF, Giannini M, Lovadino JR, dos Santos Dias CT. The effect of six polishing systems on the surface roughness of two packable resin-based composites. Am J Dent. 2002; 15(3):193-7.

97. Robinson FG, Haywood VB, Myers M. Effect of 10 percent carbamide peroxide on color of provisional restoration materials. J Am Dent Assoc. 1997; 128(6):727-31.

98. Rodrigues Neto E. Avaliação da influência do selante de superfície sobre a translucidez de resina composta. Efeito de tempos e soluções [Dissertação de Mestrado]. Araraquara: Faculdade de Odontologia da UNESP; 2004.

99. Romano JJF. Efeito da aplicação de um peróxido de carbamida a 10\% sobre a rugosidade e o desgaste de materiais restauradores estéticos submetidos à escovação [Dissertação de Mestrado]. Ribeirão Preto: Faculdade de Odontologia da USP; 2004.

100. Roulet JF, Walti C. Influence of oral fluid on composite resin and glass-ionomer cement. J Prosthet Dent. 1984; 52(2):182-9.

101. Ruyter IE, Nilner K, Möller B. Color stability of dental composite resin materials for crown and bridge veneers. Dent Mater. 1987; 3(5):246-51.

102. Santerre JP, Shajii L, Tsang H. Biodegradation of commercial dental composites by cholesterol esterase. J Dent Res. 1999; 78(8):1459-68. 
103. Santos PA. Influência da fonte de luz na estabilidade de cor de resina composta. Efeito dos meios e tempos de imersão [Tese de Doutorado]. Araraquara: Faculdade de Odontologia da UNESP; 2008.

104. Sarac D, Sarac YS, Kulunk S, Ural C, Kulunk T. The effect of polishing techniques on the surface roughness and color change of composite resins. J Prosthet Dent. 2006; 96(1):3340 .

105. Satou N, Khan AM, Matsumae I, Satou J, Shintani H. In vitro color change of composite-based resins. Dent Mater. 1989; 5(6):384-7.

106. Say EC, Civelek A, Nobecourt A, Ersoy M, Guleryuz C. Wear and microhardness of different resin composite materials. Oper Dent. 2003; 28(5):628-34.

107. Schulze KA, Marshall SJ, Gansky SA, Marshall GW. Color stability and hardness in dental composites after accelerated aging. Dent Mater. 2003; 19(7):612-9.

108. Seghi RR, Hewlett ER, Kim J. Visual and instrumental colorimetric assessments of small color differences on translucent dental porcelain. J Dent Res. 1989; 68(12):1760-4.

109. Seghi RR, Johnston WM, O'Brien WJ. Spectrophotometric analysis of color differences between porcelain systems. J Prosthet Dent. 1986; 56(1):35-40.

110. Shintani H, Satou J, Satou N, Hayashihara H, Inoue T. Effects of various finishing methods on staining and accumulation of Streptococcus mutans HS-6 on composite resins. Dent Mater. 1985; 1(6):225-7.

111. Smales RJ; Gerke DC. Clinical evaluation of light-cured anterior resin composites over periods of up to 4 years. Am. J. Dent. 1992; 5(4):208-12.

112. Soderholm KJ, Zigan M, Ragan M, Fischlschweiger W, Bergman M. Hydrolytic degradation of dental composites. J Dent Res. 1984; 63(10):1248-54.

113. Stanford WB, Fan PL, Wonzniak WT, Stanford JW. Effect of finishing on color and gloss of composites with different fillers. J Am Dent Assoc. 1985; 110(2):211-3. 
114. Stansbury FW. Curing dental resins and composites by photopolymerization. J Esthet Dent. 2000; 12(6):300-8.

115. Stober T, Gilde H, Lenz P. Color stability of highly filled composite resin materials for facings. Dent Mater. 2001; 17(1):87-94.

116. Tanoue N, Matsumura M, Atsuta M. Wear and surface roughness of current prosthetic composites after toothbrush/dentifrice abrasion. J Prosthet Dent. 2000; 84(1):93-7.

117. Tjan AHL, Chan CA. The polishability of posterior composites. J Prosthet Dent 1989; 61(2):138-46.

118. Türkün LS, Türkün M. Effect of bleaching and repolishing procedures on coffee and tea stain removal from three anterior composite veneering materials. J Esthet Restor Dent. 2004; 16(5):290-301.

119. Turssi CP, Purquerio BM, Serra MC. Wear of dental resin composites: insights into underlying processes and assessment methods - A review. J Biomed Mater Res B Appl Biomater. 2003; 65(2):280-5.

120. Um CM, Ruyter IE. Staining of resin-based veneering materials with coffee and tea. Quintessence Int. 1991; 22(5):377-86.

121. van Dijken JWV. Direct resin composite inlays/onlays: an 11 year follow-up. J Dent. 2000; 28(5):299-306.

122. van Groeningen G, Jongebloed W, Arends J. Composite degradation in vivo. Dent Mater. 1986; 2(5):225-7.

123. van Noort R, Davis LG. The surface finish of composite resin restorative materials. $\mathrm{Br}$ Dent J. 1984; 157(10):360-4.

124. Venhoven BA, de Gee AJ, Wener A, Davidson CL. Influence of filler parameters on the mechanical coherence of dental restorative resin composite. Biomaterials. 1996; 17(7):73540 .

125. von Fraunhofer JA. The surface hardness of polymeric restorative materials. Br Dent J. $1971 ; 130(6): 243-5$. 
126. Watts DC, Bertenshaw BW, Jugdev JM. pH and time-dependence of surface degradation in a compomer biomaterial. J Dent Res. 1995; 74:912.(Abstr)

127. Willems G, Lambrechts P, Braem M, Vuylsteke-Wauters M, Vanherle G. The surface roughness of enamel-to-enamel contact areas compared with the intrinsic roughness of dental resin composites. J Dent Res. 1991; 70(9):1299-305.

128. Wilson GS, Davies EH, Von Fraunhofer JA. Microhardness characteristics of anterior restorative materials. Br Dent J. 1980; 148(2):37-40.

129. Wilson NHF, Burke FJT, Mjör IA. Reasons for placement and replacement of restorations of direct restorative materials by a selected group of practitioners in the United Kingdom. Quintessence Int. 1997; 28(4):245-8.

130. Wiltshire WA, Labuschagne PW. Staining of light-cured aesthetic resin restorative materials by different staining media: na in vitro study. J Dent Assoc South Africa. 1990; 45(12):561-5.

131. Wozniak WT, Muller TP, Silverman R, Moser JB. Photographic assessment of colour changes in cold and heat-cure resins. J Oral Rehabil. 1981; 8(4):333-9.

132. Yap AU, Low JS, Ong LF. Effect of food-simulating liquids on surface characteristics of composite and polyacid-modified composite restoratives. Oper Dent. 2000; 25(3):170-6.

133. Yap AU, Lye KW, Sau CW. Surface characteristics of tooth-colored restoratives polished utilizing different polishing systems. Oper Dent. 1997; 22(6):260-5.

134. Yap AU, Teoh SH, Tan KB. Influence of water exposure on three-body wear of composite restoratives. J Biomed Mater Res. 2000; 53(5):547-53.

135. Yazici AR, Celik C, Dayangaç B, Ozgünaltay G. The effect of curing units and staining solutions on the color stability of resin composites. Oper Dent. 2007; 32(6):616-22. 
ANEXO: Artigo enviado para publicação.

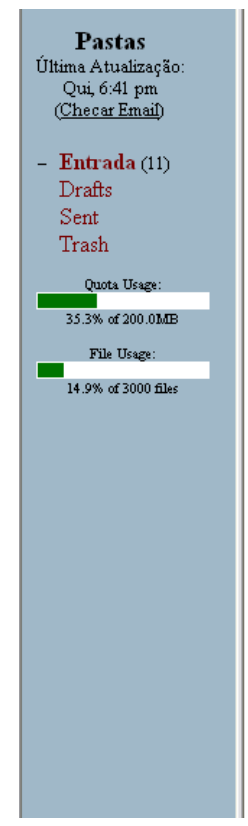

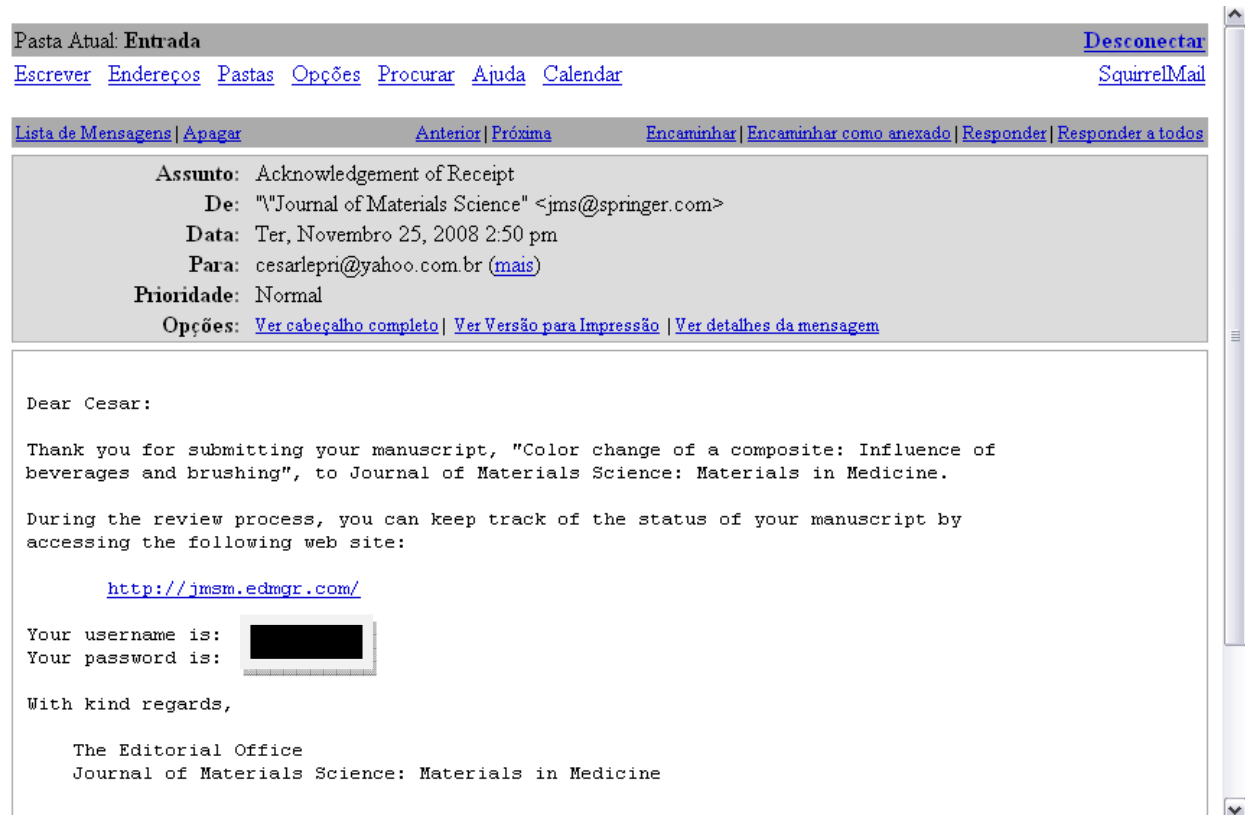

